\title{
Assessment of metabolic flux distribution in the thermophilic hydrogen producer Caloramator celer as affected by external $\mathrm{pH}$ and hydrogen partial pressure
}

Alessandro Ciranna ${ }^{1 *}$, Sudhanshu S Pawar ${ }^{2}$, Ville Santala ${ }^{1}$, Matti Karp ${ }^{1}$ and Ed WJ van Niel ${ }^{2}$

\begin{abstract}
Background: Caloramator celer is a strict anaerobic, alkalitolerant, thermophilic bacterium capable of converting glucose to hydrogen $\left(\mathrm{H}_{2}\right)$, carbon dioxide, acetate, ethanol and formate by a mixed acid fermentation. Depending on the growth conditions $\mathrm{C}$. celer can produce $\mathrm{H}_{2}$ at high yields. For a biotechnological exploitation of this bacterium for $\mathrm{H}_{2}$ production it is crucial to understand the factors that regulate carbon and electron fluxes and therefore the final distribution of metabolites to channel the metabolic flux towards the desired product.

Results: Combining experimental results from batch fermentations with genome analysis, reconstruction of central carbon metabolism and metabolic flux analysis (MFA), this study shed light on glucose catabolism of the thermophilic alkalitolerant bacterium C. celer. Two innate factors pertaining to culture conditions have been identified to significantly affect the metabolic flux distribution: culture $\mathrm{pH}$ and partial pressures of $\mathrm{H}_{2}\left(P_{\mathrm{H}_{2}}\right)$. Overall, at alkaline to neutral $\mathrm{pH}$ the rate of biomass synthesis was maximized, whereas at acidic $\mathrm{pH}$ the lower growth rate and the less efficient biomass formation are accompanied with more efficient energy recovery from the substrate indicating high cell maintenance possibly to sustain intracellular $\mathrm{pH}$ homeostasis. Higher $\mathrm{H}_{2}$ yields were associated with fermentation at acidic $\mathrm{pH}$ as a consequence of the lower synthesis of other reduced by-products such as formate and ethanol. In contrast, $P_{\mathrm{H}_{2}}$ did not affect the growth of $C$. celer on glucose. At high $P_{\mathrm{H} 2}$ the cellular redox state was balanced by rerouting the flow of carbon and electrons to ethanol and formate production allowing unaltered glycolytic flux and growth rate, but resulting in a decreased $\mathrm{H}_{2}$ synthesis.
\end{abstract}

Conclusion: $C$. celer possesses a flexible fermentative metabolism that allows redistribution of fluxes at key metabolic nodes to simultaneously control redox state and efficiently harvest energy from substrate even under unfavorable conditions (i.e. low $\mathrm{pH}$ and high $\mathrm{P}_{\mathrm{H}_{2}}$ ). With the $\mathrm{H}_{2}$ production in mind, acidic $\mathrm{pH}$ and low $P_{\mathrm{H}_{2}}$ should be preferred for a high yield-oriented process, while a high productivity-oriented process can be achieved at alkaline $\mathrm{pH}$ and high $\mathrm{P}_{\mathrm{H} 2}$.

Keywords: Caloramator, Biohydrogen production, Metabolic flux analysis, Redox state, Hydrogen tolerance, Fermentation, Pyruvate node, Metabolic shift, Ethanol, Formate

\footnotetext{
* Correspondence: alessandro.ciranna@tut.fi

${ }^{1}$ Department of Chemistry and Bioengineering, Tampere University of

Technology, Korkeakoulunkatu 8, Fl-33720 Tampere, Finland

Full list of author information is available at the end of the article
} 


\section{Introduction}

The need to circumvent environmental and social issues concerning the depletion of fossil fuels and the greenhouse gas emissions has led to exploration of alternative sources of energy. Hydrogen $\left(\mathrm{H}_{2}\right)$ is considered as a promising energy carrier for the future because of its high energy content and non-polluting properties [1]. Moreover, it can be employed as a non-fuel commodity in a variety of industrial chemo-physical processes for which the demand is increasing [2].

Dark fermentation is a potential carbon neutral process for production of $\mathrm{H}_{2}$ from organic substrates by mesophilic or thermophilic anaerobic microorganisms. In order to establish an economically viable biological process for $\mathrm{H}_{2}$ production the yield needs to be maximized [3]. Mesophilic microorganisms are not capable of producing $\mathrm{H}_{2}$ at high yield being it reported in the range of 1-2 $\mathrm{mol} \mathrm{H}_{2} / \mathrm{mol}$ hexose [4]. On the other hand, thermophiles have shown great potential for $\mathrm{H}_{2}$ generation, mainly because of the more favorable thermodynamics of the reaction at elevated temperatures which allows to generate a limited variety of by-products and to reach the theoretical yield of $4 \mathrm{~mol} \mathrm{H}_{2} / \mathrm{mol}$ hexose [5].

Caloramator celer, formerly known as Thermobrachium celere [6], is a strict anaerobic, alkalitolerant, thermophilic bacterium capable of converting $\mathrm{C}_{6}$ sugars to $\mathrm{H}_{2}, \mathrm{CO}_{2}$, acetate, ethanol and formate as major metabolites. Previous studies have shown that $C$. celer produces $\mathrm{H}_{2}$ at high yields both in a naturally occurring microbial community and in pure culture [7-9]. However, the distribution of the end metabolites can vary depending on the growth conditions allowing the accumulation of significant amounts of ethanol and formate with consequent reduction of $\mathrm{H}_{2}$ yield.

Two innate factors pertaining to culture conditions have been identified to have a prominent role in the distribution of metabolic fluxes during anaerobic fermentation in C. celer: partial pressures of $\mathrm{H}_{2}\left(P_{\mathrm{H} 2}\right)$ and culture $\mathrm{pH}$ $[8,9]$. The inhibitory effect on microbial growth and $\mathrm{H}_{2}$ production caused by $\mathrm{H}_{2}$ accumulation both in liquid and gaseous phases during the fermentation is a well known phenomenon and it has been demonstrated for several $\mathrm{H}_{2}$-producing organisms [9-13]. The fermentation medium can be easily supersaturated with $\mathrm{H}_{2}$ due to liquid-to-gas mass transfer limitations and this seems to be inevitable also at elevated temperatures [14,15]. In these conditions $\mathrm{H}_{2}$ synthesis becomes thermodynamically unfavorable and consequently the disposal of accumulated reducing equivalents in the cell is mediated by a metabolic shift towards production of more reduced metabolites, such as lactate, ethanol, acetone, butanol, or alanine [5]. As a consequence of the changes in the fermentation profile both $\mathrm{H}_{2}$ and ATP yields decrease. In previous studies C. celer achieved high $\mathrm{H}_{2}$ yields ( $\geq 3.3 \mathrm{~mol} \mathrm{H}_{2} / \mathrm{mol}$ glucose) at low culture-to-headspace volume ratio and when $\mathrm{H}_{2}$ was periodically removed from the headspace $[8,9]$. These observations suggest that in order to maximize the $\mathrm{H}_{2}$ yield in $C$. celer $P_{\mathrm{H} 2}$ in the fermentation vessel should be maintained at low level.

Culture $\mathrm{pH}$ is another factor affecting the distribution of metabolic fluxes during glucose fermentation. However, there exists a certain disagreement on the optimal $\mathrm{pH}$ to employ for $\mathrm{H}_{2}$ production [16]. Certainly, the optimal value needs to be studied case by case as it depends on the metabolic and physiological properties of the microorganism under investigation. Moreover, the ideal $\mathrm{pH}$ for cell growth may not be the same as the one for maximal $\mathrm{H}_{2}$ production [17].

Recently, a draft whole-genome sequence of $C$. celer has been obtained allowing to gain insight into the metabolic potential of this organism [18]. In particular, genomic analysis revealed pathways involved in pyruvate catabolism and end-product synthesis. To get a better understanding of the fermentative metabolism of $C$. celer under controlled conditions, a combination of experimental data from batch cultures in continuous stirred-tank reactor (CSTR), recently available genomic data and methods of metabolic flux analysis (MFA) were employed to analyze flux distribution towards end-products, taking in special consideration the effect of two innate factors, $\mathrm{pH}$ and $P_{\mathrm{H} 2}$, on hydrogen production.

\section{Results}

\section{Effect of culture $\mathrm{pH}$ on fermentative metabolism of C. celer}

The effect of culture $\mathrm{pH}$ on growth and product formation in $C$. celer was investigated for the first time under $\mathrm{pH}$-controlled conditions. Four different $\mathrm{pH}$ levels $(8,7,6,5.5)$ were tested during fermentation in a CSTR. At pH 8 and 7, C. celer showed about 3-fold higher maximum growth rates $\left(\mu_{\max }\right)$ than those obtained at $\mathrm{pH} 6$ and 5.5 (Table 1). Similarly, higher glucose consumption rates were observed at $\mathrm{pH} 8$ and 7 compared to $\mathrm{pH} 6$ and 5.5. The highest biomass formation and biomass yield were similar at $\mathrm{pH} 8$ and 7 and slightly lower at $\mathrm{pH}$ 6, while at $\mathrm{pH} 5.5$ a significant reduction was observed (Table 1). Again, cultures at $\mathrm{pH} 8$ and 7 displayed higher yield of biomass per ATP ( $\left.\mathrm{Y}_{\mathrm{X} / \mathrm{ATP}}\right)$ than the one calculated at acidic pHs, whereas the ATP yield $\left(\mathrm{Y}_{\mathrm{ATP} / \mathrm{S}}\right)$ increased at acidic conditions (Table 1$)$.

Besides growth, culture $\mathrm{pH}$ affected also the metabolite profile of $C$. celer during glucose fermentation. The highest $\mathrm{H}_{2}$ accumulation (106 mmol $\mathrm{H}_{2} / \mathrm{l}$ ) and $\mathrm{H}_{2}$ yield (2.97 $\mathrm{mol} \mathrm{H}_{2} / \mathrm{mol}$ glucose) were observed at $\mathrm{pH} 6$, while at higher $\mathrm{pH}$ their values were about 33\% lower (Table 1). In contrast, higher volumetric $\mathrm{H}_{2}$ productivity $\left(Q_{\mathrm{H} 2}\right)$ was obtained at alkaline conditions $\left(25.2 \mathrm{mmol} \mathrm{H}_{2} / \mathrm{l} / \mathrm{h}\right)$ and gradually decreased as the culture $\mathrm{pH}$ was reduced. The 
Table $1 \mathrm{pH}$-controlled batch fermentations of $\mathrm{C}$. celer on $5 \mathrm{~g} / \mathrm{l}$ of glucose at different culture pH

\begin{tabular}{|c|c|c|c|c|}
\hline & & & & \\
\hline & 8 & 7 & 6 & 5.5 \\
\hline$\mu_{\max }\left(\mathrm{h}^{-1}\right)$ & $1.50 \pm 0.05$ & $1.34 \pm 0.05$ & $0.53 \pm 0.01$ & $0.45 \pm 0.06$ \\
\hline Biomass concentration ( $\left.\mathrm{g}_{\mathrm{CDw}} / \mathrm{l}\right)$ & $0.95 \pm 0.01$ & $0.95 \pm 0.06$ & $0.76 \pm 0.01$ & $0.42 \pm 0.01$ \\
\hline$a_{\text {glucose }}{ }^{a}\left(\mathrm{mmol} / \mathrm{g}_{\mathrm{CDW}} / \mathrm{h}\right)$ & $19.6 \pm 1.4$ & $20.6 \pm 0.1$ & $14.3 \pm 0.1$ & $14.0 \pm 0.2$ \\
\hline$Y_{\text {X/ATP }}\left(\mathrm{g}_{\mathrm{CDW}} / \mathrm{mol}\right.$ ATP) & $15.4 \pm 0.7$ & $15.2 \pm 0.4$ & $6.8 \pm 0.2$ & $6.0 \pm 0.4$ \\
\hline $\mathrm{Y}_{\text {ATP/S }}(\mathrm{mol}$ ATP/mol glucose) & $2.81 \pm 0.02$ & $3.05 \pm 0.03$ & $3.54 \pm 0.33$ & $3.60 \pm 0.09$ \\
\hline $\mathrm{H}_{2}$ accumulation ( $\mathrm{mmol} \mathrm{H}_{2} / \mathrm{l}$ ) & $68.0 \pm 1.3$ & $64.2 \pm 1.1$ & $106.0 \pm 2.3$ & $91.7 \pm 0.4$ \\
\hline $\mathrm{Q}_{\mathrm{H} 2}(\mathrm{mmol} \mathrm{H} / \mathrm{l} / \mathrm{h})$ & $25.2 \pm 1.2$ & $21.0 \pm 1.3$ & $14.9 \pm 0.2$ & $13.0 \pm 0.9$ \\
\hline Product yield (mol/mol glucose) & & & & \\
\hline$Y_{X}^{b}$ & $1.29 \pm 0.05$ & $1.37 \pm 0.07$ & $1.04 \pm 0.01$ & $0.62 \pm 0.02$ \\
\hline $\mathrm{YH}_{\mathrm{H}}{ }^{\mathrm{b}}$ & $1.90 \pm 0.01$ & $1.69 \pm 0.03$ & $2.97 \pm 0.10$ & $2.48 \pm 0.03$ \\
\hline$Y_{A}^{b}$ & $1.04 \pm 0.01$ & $1.02 \pm 0.04$ & $1.33 \pm 0.08$ & $1.28 \pm 0.04$ \\
\hline$Y_{F}^{b}$ & $0.45 \pm 0.01$ & $0.37 \pm 0.11$ & $0.14 \pm 0.02$ & $0.19 \pm 0.01$ \\
\hline$Y_{E}^{b}$ & $0.35 \pm 0.01$ & $0.48 \pm 0.05$ & $0.20 \pm 0.01$ & $0.36 \pm 0.03$ \\
\hline $\mathrm{RV}_{E P}{ }^{c}$ & $2.60 \pm 0.03$ & $2.65 \pm 0.13$ & $3.36 \pm 0.09$ & $3.19 \pm 0.02$ \\
\hline $\mathrm{HAc} / \mathrm{EtOH}$ & $2.96 \pm 0.11$ & $2.15 \pm 0.30$ & $6.83 \pm 0.67$ & $3.60 \pm 0.14$ \\
\hline Carbon recovery (\%) & $88.6 \pm 1.1$ & $99.8 \pm 1.5$ & $100.7 \pm 2.8$ & $93.5 \pm 1.6$ \\
\hline Redox recovery (\%) & $94.4 \pm 0.6$ & $99.2 \pm 0.7$ & $98.4 \pm 3.2$ & $93.6 \pm 2.1$ \\
\hline
\end{tabular}

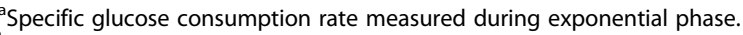

${ }^{b} \mathrm{Y}$ indicates the yield of product (where $\mathrm{x}=$ biomass, $\mathrm{H}_{2}=$ hydrogen, $\mathrm{A}=$ acetate, $\mathrm{F}=$ formate and $\mathrm{E}=$ =ethanol) per mole of glucose consumed.

${ }^{c}$ Total molar reduction values of reduced end-products $\left(R V_{E P}=Y_{H 2}+2 * Y_{E}\right)$ [19].

lower $\mathrm{H}_{2}$ production observed at $\mathrm{pH} 8$ and 7 was accompanied by an increase of formate and ethanol yields, both being about 2-fold higher compared to those observed at $\mathrm{pH} 6$ (Table 1). The lower $\mathrm{RV}_{\mathrm{EP}}$ (total molar reduction values of reduced end-products) [19] and the acetate-to-ethanol ratio calculated for fermentation at $\mathrm{pH} 8$ and 7 reflected the increased production of formate and ethanol (Table 1).

\section{Combined effect of culture $\mathrm{pH}$ and $P_{\mathrm{H} 2}$ on fermentative metabolism of $C$. celer Combined effect of $\mathrm{pH}$ and $\mathrm{P}_{\mathrm{H} 2}$ on growth and metabolite production profiles}

To investigate the combined effect of $\mathrm{pH}$ and $P_{\mathrm{H} 2}$ on growth, product formation and carbon flux distribution in C. celer, four different experimental conditions were tested using $\mathrm{pH}$ and application of $\mathrm{N}_{2}$ sparging as variables (Case I-IV). Sparging the reactor with $\mathrm{N}_{2}$ did not significantly affect the growth of $C$. celer at $\mathrm{pH} 7$ and 6 (Figure 1A). In fact, despite the remarkable difference in the $P_{\mathrm{H} 2 \max }$ in the reactor headspace with and without $\mathrm{N}_{2}$ sparging, similar growth rates and biomass yields were achieved within the same $\mathrm{pH}$ level (Table 2). On the other hand, at same sparging conditions the $\mathrm{pH}$ had a higher impact on growth with about 2.5-fold reduction of $\mu_{\max }$ (Table 2) and a slower overall glucose consumption rate observed at $\mathrm{pH} 6$
(Figure 1B). Also, $\mathrm{Y}_{\mathrm{X} / \mathrm{ATP}}$ was lower at $\mathrm{pH} \mathrm{6,} \mathrm{especially}$ under sparging conditions (Table 2). Nevertheless, despite a slower growth at $\mathrm{pH}$ 6, the highest biomass formation was comparable to the one reached at $\mathrm{pH} 7$ (about $1 \mathrm{~g}_{\mathrm{CDW}} / \mathrm{l}$ ) (Figure 1A).

Both culture $\mathrm{pH}$ and $P_{\mathrm{H} 2}$ influenced the carbon flux distribution and the end-product profile in C. celer during glucose fermentation. The beneficial effect of $\mathrm{H}_{2}$ removal from the reactor on $\mathrm{H}_{2}$ production was more evident at $\mathrm{pH} 6$ (Case III and IV). In fact, at this $\mathrm{pH}$, when $\mathrm{N}_{2}$ sparging was applied, $\mathrm{H}_{2}$ accumulation increased by about $26 \%$ and $\mathrm{H}_{2}$ yield by $19 \%$ (Case III) (Figure 1C; Table 2). On the other hand, at pH 7 (Case I and II) the effect of $P_{\mathrm{H} 2}$ on $\mathrm{H}_{2}$ production was marginal with a $9 \%$ and $13 \%$ increase at low $P_{\mathrm{H} 2}$ for $\mathrm{H}_{2}$ accumulation and $\mathrm{H}_{2}$ yield, respectively (Case $I$ ). In addition, applying $\mathrm{N}_{2}$ sparging did not affect $Q_{\mathrm{H} 2}$ within the same $\mathrm{pH}$ level. At the same sparging condition acidic $\mathrm{pH}$ promoted higher $\mathrm{H}_{2}$ accumulation and $\mathrm{H}_{2}$ yield, while neutral $\mathrm{pH}$ favored higher $Q_{\mathrm{H} 2}$ (Figure 1C; Table 2). In fact, when $\mathrm{N}_{2}$ sparging was applied (Case $I$ and $I I I) \mathrm{H}_{2}$ accumulation increased by $32 \%$ and $\mathrm{H}_{2}$ yield by $33 \%$ as $\mathrm{pH}$ set-point was lowered from 7 to 6 . Even so, the $Q_{\mathrm{H} 2}$ at $\mathrm{pH} 7$ was about $36 \%$ higher than at $\mathrm{pH}$ 6. A similar trend could be observed without $\mathrm{N}_{2}$ sparging (Case II and $I V$ ), although the differences between $\mathrm{H}_{2}$ accumulation and $\mathrm{H}_{2}$ yield at pH 6 and pH 7 were significant but less pronounced. 


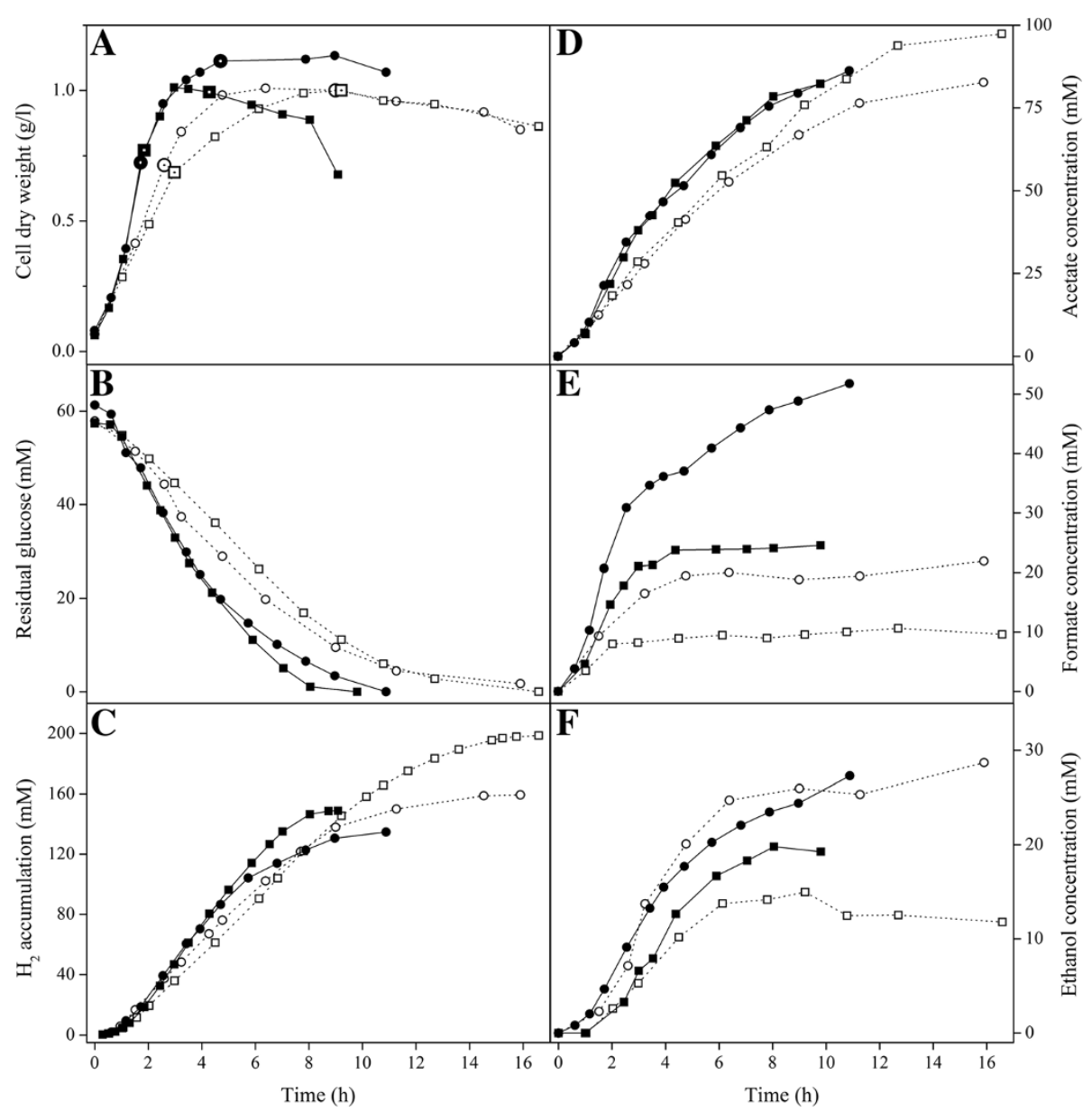

Figure 1 Growth and product formation by $\mathrm{C}$. celer in $\mathrm{pH}$-controlled batch fermentations performed at $\mathrm{pH} 7$ and 6 , with and without $\mathbf{N}_{\mathbf{2}}$ sparging. Growth (A), glucose consumption (B) and end product accumulation (C-F) profiles of C. celer cultured with $10 \mathrm{~g} / \mathrm{l}$ glucose at pH 7 (straight lines) with $\mathrm{N}_{2}$ sparging (Case I, filled squares) and without $\mathrm{N}_{2}$ sparging (Case II, filled circles), and at pH 6 (dashed lines) with $\mathrm{N}_{2}$ sparging (Case III, open squares) and without $\mathrm{N}_{2}$ sparging (Case N, open circles). Larger symbols in panel A represent sampling points for ATP, NADH and $\mathrm{NAD}^{+}$measurements. Data are from one representative fermentation per condition.

Carbon and electron flow at the pyruvate and acetyl-CoA nodes was affected by both $\mathrm{pH}$ and $P_{\mathrm{H} 2}$. While acetate accumulation profile and yield were minimally influenced by the $P_{\mathrm{H} 2}$, formate and ethanol synthesis significantly increased at both $\mathrm{pH}$ levels when $\mathrm{H}_{2}$ concentration was allowed to build up in the reactor (Case II and IV) (Figure 1D, 1E, 1F; Table 2). Specifically, formate accumulation and yield were about 2-fold higher without $\mathrm{N}_{2}$ sparging regardless of the culture $\mathrm{pH}$ (Case II and $I V$ ), whereas the effect of $P_{\mathrm{H} 2}$ on ethanol production was more drastic at $\mathrm{pH} 6$ (Case IV) with an increase of accumulation and yield of 2.5- and 4-fold, respectively. The ability of $C$. celer to produce reduced end-products $\left(\mathrm{RV}_{\mathrm{EP}}\right)$, i.e. $\mathrm{H}_{2}$ and ethanol, remained unchanged under different $P_{\mathrm{H} 2}$ (Table 2). On the other hand, acetate-to-ethanol ratio showed that at the acetyl-CoA node the redirection of carbon and electron flow toward ethanol synthesis is less favorable at low $P_{\mathrm{H} 2}$, especially at $\mathrm{pH} 6$ (Case III) where the highest acetate-to-ethanol ratio of 14.2 was observed (Table 2).

Acidic $\mathrm{pH}$ (Case III and IV) promoted a slight increase of acetate accumulation and yield, whereas formate accumulation and yield were reduced by more than 2 -fold at $\mathrm{pH} 6$ both with and without gas stripping (Case III and IV) (Figure 1D, 1E; Table 2). A drastic reduction of ethanol synthesis occurred only at acidic $\mathrm{pH}$ with $\mathrm{N}_{2}$ sparging (Case III), while at high $P_{\mathrm{H} 2}$ both ethanol accumulation and yield remained at high level regardless of the culture $\mathrm{pH}$ (Case II and IV) (Figure 1F; Table 2). The increase of $\mathrm{RV}_{\mathrm{EP}}$ from 2.8-2.9 at $\mathrm{pH} 7$ (Case I and II) to 3.3-3.4 at pH 6 (Case III and IV) indicates that $\mathrm{pH}$ influenced the conversion of glucose to reduced end-products $\left(\mathrm{H}_{2}\right.$ and ethanol). The flux at the acetyl-CoA node was affected by $\mathrm{pH}$ only when sparging was applied resulting in a 3 -fold increase of the acetate-to-ethanol ratio at $\mathrm{pH} 6$ (Case III), while 
Table $2 \mathrm{pH}$-controlled batch fermentations of $\mathrm{C}$. celer on $10 \mathrm{~g} / \mathrm{l}$ of glucose at $\mathrm{pH} 7$ and 6 , with and without $\mathrm{N}_{2}$ sparging

\begin{tabular}{|c|c|c|c|c|}
\hline & \multicolumn{2}{|c|}{$\mathrm{pH} 7$} & \multicolumn{2}{|c|}{$\mathrm{pH} 6$} \\
\hline & $\mathrm{N}_{2}$ sparging (Case I) & No sparging (Case II) & $\mathrm{N}_{2}$ sparging (Case III) & No sparging (Case IV) \\
\hline$P_{\mathrm{H} 2 \max }(\mathrm{kPa})$ & 8 & 69 & 6 & 74 \\
\hline$\mu_{\max }\left(h^{-1}\right)$ & $1.09 \pm 0.09$ & $1.09 \pm 0.08$ & $0.43 \pm 0.03$ & $0.38 \pm 0.05$ \\
\hline Biomass concentration (g/l) & $0.99 \pm 0.03$ & $1.13 \pm 0.01$ & $1.02 \pm 0.03$ & $1.01 \pm 0.01$ \\
\hline$Y_{\text {X/ATP }}\left(g_{C D W} / \mathrm{mol}\right.$ ATP $)$ & $11.5 \pm 0.3$ & $9.3 \pm 0.1$ & $6.3 \pm 0.4$ & $7.9 \pm 0.2$ \\
\hline$Y_{\text {ATP/S }}(\mathrm{mol}$ ATP/mol glucose) & $3.24 \pm 0.03$ & $3.18 \pm 0.02$ & $3.4 \pm 0.08$ & $3.48 \pm 0.17$ \\
\hline$Q_{\mathrm{H} 2}(\mathrm{mmol} \mathrm{H} / \mathrm{l} / \mathrm{h})$ & $27.1 \pm 1.5$ & $33.0 \pm 0.1$ & $19.9 \pm 0.8$ & $20.6 \pm 0.5$ \\
\hline \multicolumn{5}{|l|}{ Product yield (mol/mol glucose) } \\
\hline$Y_{X}^{a}$ & $0.71 \pm 0.01$ & $0.75 \pm 0.03$ & $0.72 \pm 0.01$ & $0.75 \pm 0.01$ \\
\hline $\mathrm{YH}^{\mathrm{a}}{ }^{\mathrm{a}}$ & $2.32 \pm 0.13$ & $2.06 \pm 0.13$ & $3.10 \pm 0.06$ & $2.60 \pm 0.03$ \\
\hline$Y_{A}^{a}$ & $1.24 \pm 0.01$ & $1.28 \pm 0.01$ & $1.47 \pm 0.07$ & $1.35 \pm 0.02$ \\
\hline$Y_{F}{ }^{a}$ & $0.37 \pm 0.02$ & $0.71 \pm 0.12$ & $0.14 \pm 0.07$ & $0.33 \pm 0.06$ \\
\hline$Y_{E}^{a}$ & $0.27 \pm 0.01$ & $0.37 \pm 0.01$ & $0.10 \pm 0.01$ & $0.39 \pm 0.03$ \\
\hline $\mathrm{RV}_{E P} \mathrm{~b}^{\mathrm{b}}$ & $2.87 \pm 0.11$ & $2.8 \pm 0.12$ & $3.31 \pm 0.08$ & $3.39 \pm 0.03$ \\
\hline $\mathrm{HAc} / \mathrm{EtOH}$ & $4.5 \pm 0.2$ & $3.5 \pm 0.1$ & $14.2 \pm 1.0$ & $3.4 \pm 0.3$ \\
\hline Carbon recovery (\%) & $92.6 \pm 0.6$ & $94.0 \pm 0.7$ & $94.8 \pm 4.2$ & $100.3 \pm 1.9$ \\
\hline Redox recovery (\%) & $90.0 \pm 0.6$ & $97.5 \pm 0.6$ & $93.2 \pm 4.1$ & $102.3 \pm 2.2$ \\
\hline
\end{tabular}

${ }^{a} \mathrm{Y}$ indicates the yield of product (where $\mathrm{x}=$ biomass, $\mathrm{H}_{2}=$ hydrogen, $\mathrm{A}=$ =acetate, $\mathrm{F}=$ formate and $\mathrm{E}=$ =thanol) per mole of glucose consumed.

${ }^{b}$ Total molar reduction values of reduced end-products $\left(R V_{E P}=Y_{H 2}+2 * Y_{E}\right)[19]$.

no variation in the ratio was observed when $\mathrm{H}_{2}$ concentration was allowed to build up in the reactor.

\section{Combined effect of $\mathrm{pH}$ and $\mathrm{P}_{\mathrm{H} 2}$ on ATP and redox levels}

To evaluate the effect of $\mathrm{pH}$ and $P_{\mathrm{H} 2}$ on energy and redox metabolism of $C$. celer, intracellular ATP, NADH and $\mathrm{NAD}^{+}$were measured in the exponential and stationary phase of growth (Figure 1A). At the same culture pH ATP levels were not significantly different both in exponential and stationary phase regardless of the application of $\mathrm{N}_{2}$ sparging, suggesting that intracellular ATP was not affected by the $P_{\mathrm{H} 2}$ (Table 3 ). In contrast, culture $\mathrm{pH}$ showed a more significant influence on the ATP levels. In the exponential phase ATP was at least 2-fold higher at $\mathrm{pH} 7$ (Case $I$ and $I$ ) compared to pH 6 (Case III and IV). In the stationary phase intracellular ATP at pH 7 doubled (Case $I$ and II), while at $\mathrm{pH} 6$ was reduced by one-third (Case III and IV). As a consequence the difference between the ATP levels observed at pH 7 and 6 increased from 2-fold in

Table 3 Intracellular ATP, NADH and NAD ${ }^{+}$concentrations, and NADH/NAD ${ }^{+}$ratio

\begin{tabular}{|c|c|c|c|c|}
\hline & \multicolumn{2}{|c|}{ pH 7} & \multicolumn{2}{|c|}{$\mathrm{pH} 6$} \\
\hline & $\mathrm{N}_{2}$ sparging (Case I) & No sparging (Case II) & $\mathrm{N}_{2}$ sparging (Case III) & No sparging (Case IV) \\
\hline \multicolumn{5}{|l|}{ ATP ( $\mu$ moles/g biomass) } \\
\hline Exponential phase & $0.097 \pm 0.005$ & $0.117 \pm 0.003$ & $0.046 \pm 0.003$ & $0.043 \pm 0.003$ \\
\hline Stationary phase & $0.254 \pm 0.025$ & $0.199 \pm 0.017$ & $0.029 \pm 0.002$ & $0.030 \pm 0.002$ \\
\hline \multicolumn{5}{|c|}{ NADH ( $\mu$ moles/g biomass) } \\
\hline Exponential phase & $0.019 \pm 0.004$ & $0.021 \pm 0.005$ & $0.007 \pm 0.002$ & $0.011 \pm 0.002$ \\
\hline Stationary phase & $0.015 \pm 0.003$ & $0.025 \pm 0.003$ & $0.010 \pm 0.002$ & $0.015 \pm 0.002$ \\
\hline \multicolumn{5}{|c|}{$\mathrm{NAD}^{+}$( $\mu$ moles/g biomass) } \\
\hline Exponential phase & $0.239 \pm 0.011$ & $0.335 \pm 0.032$ & $0.231 \pm 0.002$ & $0.271 \pm 0.001$ \\
\hline Stationary phase & $0.201 \pm 0.015$ & $0.205 \pm 0.038$ & $0.005 \pm 0.001$ & $0.010 \pm 0.001$ \\
\hline \multicolumn{5}{|l|}{$\mathrm{NADH} / \mathrm{NAD}^{+}(\mathrm{mol} / \mathrm{mol})$} \\
\hline Exponential phase & $0.08 \pm 0.02$ & $0.06 \pm 0.02$ & $0.03 \pm 0.01$ & $0.04 \pm 0.01$ \\
\hline Stationary phase & $0.07 \pm 0.01$ & $0.13 \pm 0.01$ & $1.77 \pm 0.23$ & $1.56 \pm 0.39$ \\
\hline
\end{tabular}


exponential phase to about 7- to 8-fold in the stationary phase (Table 3).

In the exponential phase the $\mathrm{NADH} / \mathrm{NAD}^{+}$ratio measured with and without $\mathrm{N}_{2}$ sparging resulted to be similar at both $\mathrm{pH}$ levels (Table 3). However, at $\mathrm{pH} 7$ the $\mathrm{NADH} / \mathrm{NAD}^{+}$ratio increased by 2 -fold (from 0.06 to 0.13 ) during the stationary phase when $P_{\mathrm{H} 2}$ reached about $56 \mathrm{kPa}$ (Case II), while it remained unaffected when $P_{\mathrm{H} 2}$ was kept low by $\mathrm{N}_{2}$ sparging (Case I). Surprisingly, a dramatic increase of the $\mathrm{NADH} / \mathrm{NAD}^{+}$ratio was observed during the stationary phase at $\mathrm{pH} 6$ (Case III and IV). This was caused by an expected depletion of $\mathrm{NAD}^{+}$pool rather than an increase in intracellular NADH concentration (Table 3).

\section{Metabolic flux analysis under different $\mathrm{pH}$ and $P_{\mathrm{H} 2}$}

To investigate more in detail the effect of $\mathrm{pH}$ and $\mathrm{N}_{2}$ sparging on the fermentative metabolism of C. celer, metabolic flux analysis (MFA) was carried out for Case I to $I V$ at different growth phases (Figure 2). A node analysis was performed to estimate the distribution of the fluxes at key metabolic branch points (Figure 3). In the proposed metabolic network of C. celer (Figure 2A; Additional file 1: Table S1), phosphoenolpyruvate (PEP) is the first important intermediate being potentially used by three reactions $(v 1, v 6, v 11)$ (Figure 3A). Generally, most of the PEP was converted to pyruvate by reaction $v 1$ and $v 6$ especially as the fermentation proceeded. In the exponential phase only a fraction of the PEP was converted to oxaloacetate $(v 11)$ and almost none in the stationary phase. The distribution at this metabolic node during exponential phase was minimally affected by the difference in $P_{\mathrm{H} 2}$ at both $\mathrm{pH}$. On the other hand, the conversion of PEP to oxaloacetate ( $v 11)$ was affected by $\mathrm{pH}$. In fact, at $\mathrm{pH} 7$ (Case I and II) the PEP directed to the "malate shunt" (v11-v13) in the exponential phase was almost 2-fold higher than at $\mathrm{pH} 6$ (Case III and $I V$ ). Given the higher growth rate observed at pH 7 (Figure 1A, Table 2), a higher flux through the "malate shunt" was not surprising since it served as the only source of NADPH for biomass synthesis.

The distribution of the flux at the pyruvate node determines the size of the reduced ferredoxin $\left(\mathrm{Fd}_{\text {red }}\right)$ available for $\mathrm{H}_{2}$ production since only conversion of pyruvate to acetyl-CoA by pyruvate:ferredoxin oxidoreductase (PFOR) generates reducing equivalents. Both $\mathrm{pH}$ and $P_{\mathrm{H} 2}$, as well as the growth phase, influenced the fluxes at this node (Figure 3B). When $\mathrm{H}_{2}$ was stripped from the reactor, the $v 15 / v 14$ ratio in the exponential phase almost doubled both at $\mathrm{pH} 7$ (Case I) and $\mathrm{pH} 6$ (Case III) suggesting that lower $P_{\mathrm{H} 2}$ directs the flux through PFOR. A more dramatic effect on flux distribution at this node was exerted by the culture $\mathrm{pH}$. In the exponential phase

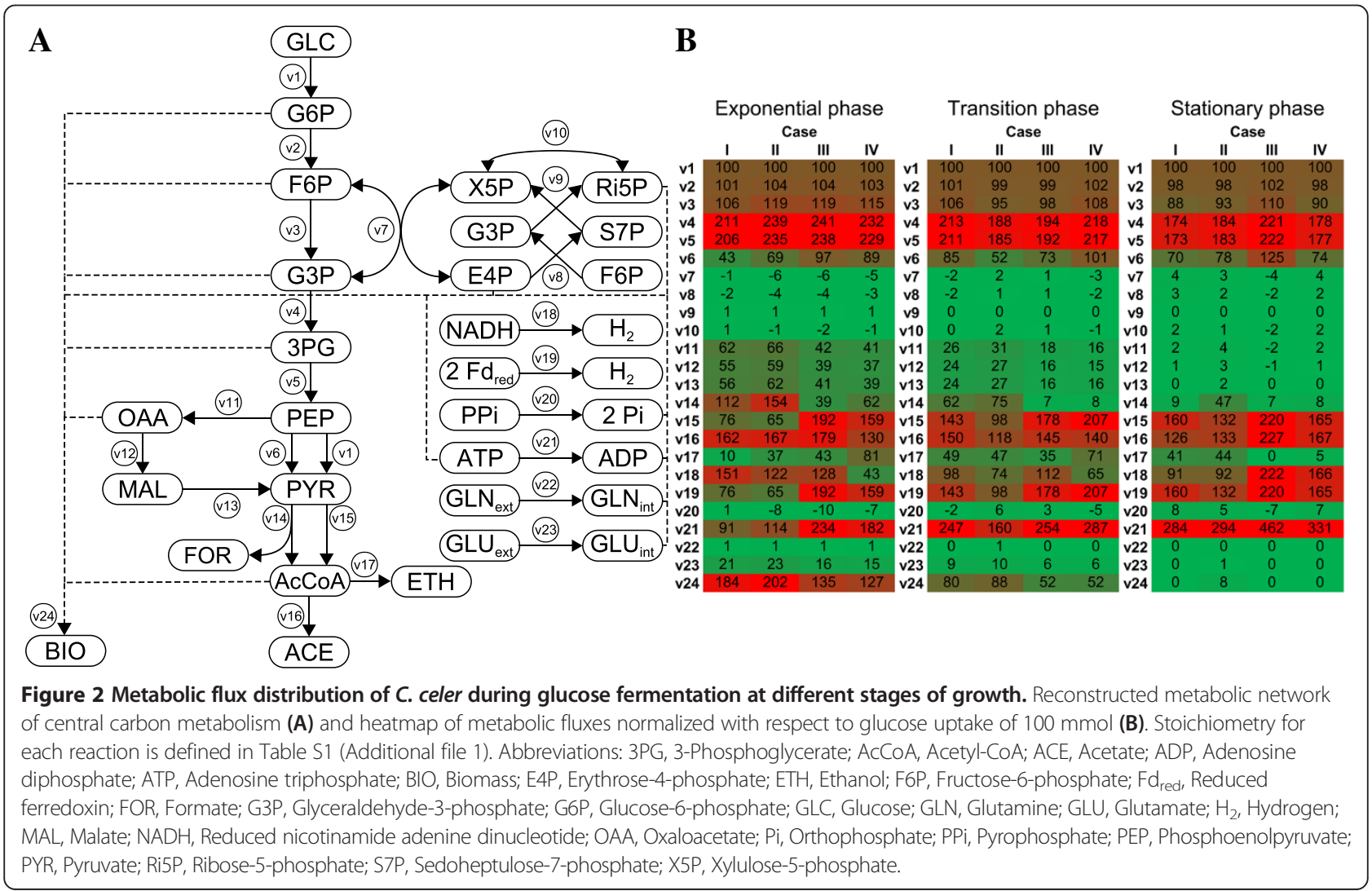




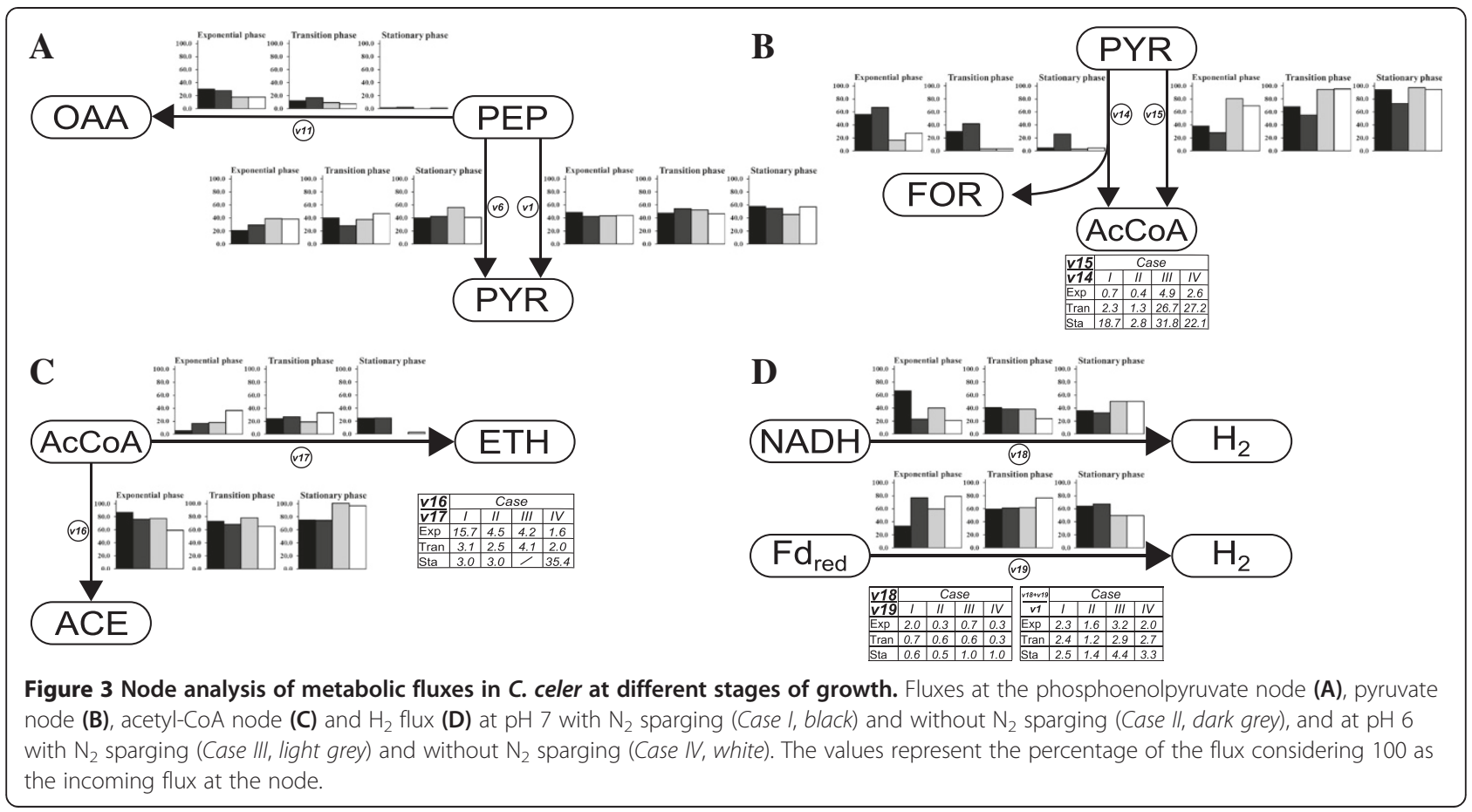

neutral $\mathrm{pH}$ favored acetyl-CoA formation through pyruvate formate lyase (PFL) $(v 15 / v 14<1$ in Case $I$ and $I I)$, whereas at acidic $\mathrm{pH}$ pyruvate was mainly directed through PFOR $(v 15 / v 14>1$ in Case III and IV). Although decreased in the later stage of growth, a significant formate flux was measured at $\mathrm{pH} 7$ when sparging was not applied (Case II), whereas it almost ceased in all other conditions (Case I, III and IV). In general, a direct correlation was observed between formate flux $(v 14)$ and the growth rate (Figure 4A). Routing the carbon and electron flow through PFL has negative implication for $\mathrm{H}_{2}$ production since this reaction does not supply $\mathrm{Fd}_{\text {red. }}$ This is confirmed by the negative correlation existing between the formate flux (v14) and the Fd-dependent $\mathrm{H}_{2}$ flux (v19) estimated at different growth phases (Figure 5A). In addition, the importance of the flux distribution at the pyruvate node for $\mathrm{H}_{2}$ production in C. celer is also highlighted by the correlation between the fraction of the flux through PFOR in the exponential phase and the overall $\mathrm{H}_{2}$ yield (Figure 4B).

Acetyl-CoA is another critical intermediate in C. celer metabolism. Conversion of acetyl-CoA to acetate ( $v 16)$ generates one extra ATP, while ethanol production is used
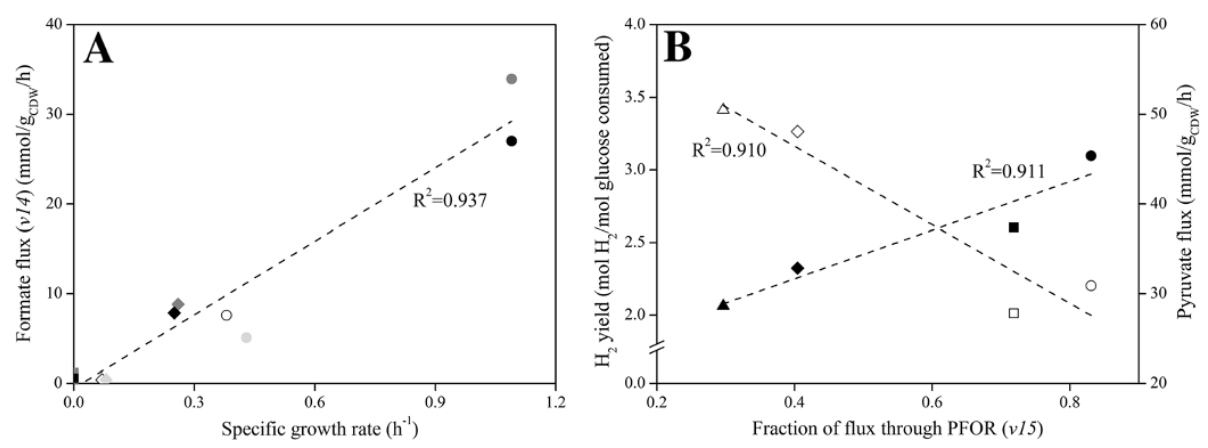

Figure 4 Correlation between distribution of fluxes at the pyruvate node and growth rate, $\mathrm{H}_{2}$ yield and pyruvate flux. Correlation between formate flux (V14) and growth rate (A) in exponential phase (circles), transition phase (diamonds) and stationary phase (squares) at pH 7 with $\mathrm{N}_{2}$ sparging (Case I, black) and without $\mathrm{N}_{2}$ sparging (Case II, dark grey), and at pH 6 with $\mathrm{N}_{2}$ sparging (Case III, light grey) and without $\mathrm{N}_{2}$ sparging (Case $N$, white). Correlation between fraction of flux through PFOR during exponential phase and pyruvate flux during exponential phase (open symbo/s), and overall $\mathrm{H}_{2}$ yield (filled symbols) (B) at pH 7 with $\mathrm{N}_{2}$ sparging (Case I, diamonds) and without $\mathrm{N}_{2}$ sparging (Case II, triangles), and at $\mathrm{pH} 6$ with $\mathrm{N}_{2}$ sparging (Case III, circles) and without $\mathrm{N}_{2}$ sparging (Case IV, squares). 

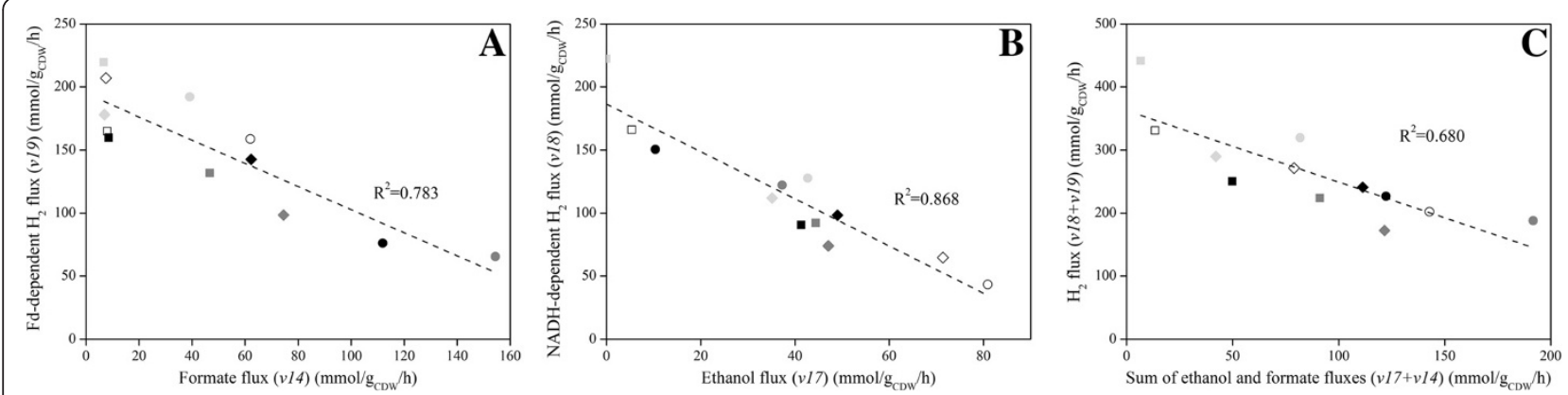

Figure $\mathbf{5}$ Correlation between formate and ethanol fluxes, and $\mathbf{H}_{\mathbf{2}}$ fluxes. Correlation between formate flux ( $\left.\mathrm{v} / 4\right)$ and Fd-dependent $\mathrm{H}_{2}$ flux $(v 19)(\mathbf{A})$, between ethanol flux (v17) and NADH-dependent $\mathrm{H}_{2}$ flux (v18) (B), and between the sum of formate and ethanol fluxes ( $14+v 17$ ) and overall $\mathrm{H}_{2}$ flux (v18+v19) (C) in exponential phase (circles), transition phase (diamonds) and stationary phase (squares) at pH 7 with $\mathrm{N}_{2}$ sparging (Case I, black) and without $\mathrm{N}_{2}$ sparging (Case II, dark grey), and at pH 6 with $\mathrm{N}_{2}$ sparging (Case III, light grey) and without $\mathrm{N}_{2}$ sparging (Case IV, white).

as an electron sink for the oxidation of $\mathrm{NADH}(v 17)$. Although production of acetate was generally favored, ethanol flux varied depending of the experimental conditions (Figure $3 \mathrm{C}$ ). Applying $\mathrm{N}_{2}$ sparging to prevent $\mathrm{H}_{2}$ building up in the reactor promoted a lower ethanol flux in the exponential phase (Case I and III). In particular, the flux directed to ethanol was 3- and 2-fold lower for Case I and III respectively, and similarly the $v 16 / v 17$ ratio was 3 - and 2.5-fold higher suggesting that low $P_{\mathrm{H} 2}$ favored acetate over ethanol production in the exponential phase. Ethanol flux in the exponential phase was lower at $\mathrm{pH} 7$ compared to $\mathrm{pH} 6$ at both sparging conditions. However, while at pH 6 (Case III and IV) the ethanol production completely ceased in the stationary phase, at pH 7 (Case I and II) it started increasing at the end of the exponential phase resulting in about $25 \%$ of the flux to be directed to ethanol regardless of the $P_{\mathrm{H} 2}$ in the reactor. Since conversion of acetyl-CoA to ethanol requires $\mathrm{NADH}$ as reduced cofactor, it competes with $\mathrm{NADH}$-dependent $\mathrm{H}_{2}$ production for the use of reducing equivalents. Figure $5 \mathrm{~B}$ supports this scenario showing that in $C$. celer $\mathrm{NADH}$-dependent $\mathrm{H}_{2}$ flux (v18) estimated at different growth phases was negatively correlated with ethanol flux (v17).

Data from MFA was also used to analyze the $\mathrm{H}_{2}$ flux and how its two components, the NADH-dependent (v18) and the Fd-dependent (v19) $\mathrm{H}_{2}$ production, contribute to it (Figure 3D). In the exponential phase $\mathrm{N}_{2}$ sparging had a great effect on the NADH-dependent $\mathrm{H}_{2}$ flux $(v 19)$ that increased from 23.4 (Case II) to $66.5 \%$ (Case I) of the total $\mathrm{H}_{2}$ flux at $\mathrm{pH} 7$ and from 20.9 (Case $I V)$ to $40.2 \%$ (Case III) at $\mathrm{pH}$ 6. However, no evident trend can be identified in the distribution of $\mathrm{H}_{2}$ flux with respect of the culture $\mathrm{pH}$ in this growth phase. In general, with the exception of Case I, during the exponential phase Fd-dependent proton reduction $(v 19)$ was the favorite reaction for $\mathrm{H}_{2}$ synthesis. As the fermentation entered in the stationary phase, at pH 7 (Case $I$ and $I I$ ) Fd-dependent $\mathrm{H}_{2}$ flux (v19) was almost twice the NADH-dependent $\mathrm{H}_{2}$ flux (v18), while at $\mathrm{pH} 6$ (Case III and $I V)$ the $\mathrm{H}_{2}$ flux was equally distributed between the Fd-dependent ( $v 19)$ and the NADH-dependent reaction $(v 18)$. When comparing the overall $\mathrm{H}_{2}$ flux $(v 18+v 19)$ normalized by glucose uptake $(v 1)$ it is clear that low $P_{\mathrm{H} 2}$ achieved by $\mathrm{N}_{2}$ sparging (Case $I$ and $I I I$ ) promoted higher $\mathrm{H}_{2}$ production in $C$. celer, whereas when $\mathrm{H}_{2}$ was allowed to accumulate in the reactor (Case $I I$ and $I V$ ) $\mathrm{H}_{2}$ evolution suffered (Figure 3D). Similarly, running the fermentation at acidic $\mathrm{pH}$ (Case $I I I$ and $I V$ ) instead of at neutral $\mathrm{pH}$ (Case $I$ and $I I$ ) increased the disposal of reducing equivalent through $\mathrm{H}_{2}$ production, especially in the stationary phase when fluxes of the competing reactions ( $v 14$ and $v 17$ ) were minimal (Figure 5C).

\section{Discussion}

\section{Generation and consumption of reducing equivalents in C. celer}

During glucose catabolism reducing equivalents are generated in the form of $\mathrm{NADH}$ or $\mathrm{Fd}_{\text {red }}$. These cofactors need to be reoxidized allowing the glycolytic flux to proceed. During fermentation this can be achieved through different reactions involving the synthesis of reduced molecules such as $\mathrm{H}_{2}$, ethanol, lactate, butyrate and alanine. Specifically, C. celer can produce NADH during the oxidation of glyceraldehyde-3-phosphate by an $\mathrm{NAD}^{+}$-dependent glyceraldehyde-3-phosphate dehydrogenase (GAPDH, TCEL_00702) and $\mathrm{Fd}_{\text {red }}$ in the oxidation of pyruvate to acetyl-CoA by pyruvate:ferredoxin oxidoreductases (PFOR, TCEL_02202-02206/TCEL_01566) (Figure 2A; Additional file 1: Table S1). While in C. celer glycolysis (Embden-Meyerhof pathway) yields $2 \mathrm{NADH}$ per one glucose metabolized, generation of $\mathrm{Fd}_{\text {red }}$ is dependent on flux distribution at the pyruvate node. At this node pyruvate is non-oxidatively dissimilated to acetyl-CoA and formate by pyruvate formate lyase (PFL, TCEL_00503) or oxidatively decarboxylated to acetyl-CoA by PFOR. Only the latter generates $\mathrm{Fd}_{\mathrm{red}}$ and when $100 \%$ of the flux goes 
through PFOR, generation of reducing equivalents is maximized resulting in the formation of $2 \mathrm{NADH}$ and $4 \mathrm{Fd}_{\text {red }}$. If all reduced electron carriers were recycled by hydrogenases, the complete oxidation of one molecule of glucose would yield $4 \mathrm{H}_{2}$ molecules. The genome of $C$. celer contains two clusters coding for putative [FeFe]-hydrogenases (TCEL_00581-00584/TCEL_01273-01277) and one cluster coding for a putative [NiFe]-hydrogenase (TCEL_0018700205) (Figure 2A; Additional file 1: Table S1). Based on similarity of the gene organization within the clusters and the high homology with the cytosolic enzyme complex of Caldanaerobacter subterraneus subsp. tengcongensis [12], the two [FeFe]-hydrogenases most likely utilize $\mathrm{NADH}$ as an electron donor for proton reduction. The [NiFe]-hydrogenase is predicted to be a multimeric Fd-dependent membrane-bound enzyme similar to the $\mathrm{MBH}$ complex characterized in Pyrococcus furiosus [20]. In this species $\mathrm{MBH}$ couples the oxidation of $\mathrm{Fd}_{\text {red }}$ with energy conservation by forming an ion gradient that can be used to generate ATP via a membrane-bound ATP synthase.

However, recycling reducing equivalent through $\mathrm{H}_{2}$ production is not always thermodynamically favorable. At a given temperature the oxidation of reduced cofactors (particularly of $\mathrm{NADH}$ ) by hydrogenases is a function of the $\mathrm{H}_{2}$ concentration [5]. Supersaturation of the aqueous phase with $\mathrm{H}_{2}$ can easily occur due to limitation of liquid-to-gas mass transfer rate [14,15]. As a consequence, at high $\mathrm{H}_{2}$ concentrations the disposal of accumulated reducing equivalents in the cell is mediated by a metabolic shift towards production of more reduced metabolites such as ethanol, lactate, and alanine. The genome analysis revealed that in $C$. celer the only alternative for $\mathrm{NADH}$ oxidation is ethanol production, since no lactate dehydrogenase nor NAD:ferredoxin oxidoreductase (NFOR) were identified (Figure 2A; Additional file 1: Table S1). In addition, although $C$. celer encodes a complete pathway for butyrate synthesis that would consume NADH, no butyrate was detected as end-product in this study. Ethanol production mediated by putative bifunctional acetaldehyde/alcohol dehydrogenase (TCEL_01373) and alcohol dehydrogenase (TCEL_00064) has been shown to increase at high $P_{\mathrm{H} 2}$ validating the hypothesis that this pathway serves as an alternative to hydrogenase for NADH reoxidation $[8,9]$.

As in $C$. celer the only possibility for $\mathrm{Fd}_{\text {red }}$ oxidation relies on the activity of the ferredoxin-dependent $\mathrm{MBH}$ complex, the distribution of carbon and electron flow at the pyruvate nodes dictates the size of the $\mathrm{Fd}_{\text {red }}$ pool available for $\mathrm{H}_{2}$ production. Despite the similar standard Gibbs energy $\left(\Delta G^{o \prime}\right)[19]$, the reaction catalyzed by PFOR is expected to be less favorable at high $\mathrm{H}_{2}$ concentration due to the increased Gibbs energy $\left(\Delta G^{\prime}\right)$ of the ferredoxin oxidation by $\mathrm{H}_{2}$ production, whereas the thermodynamics of the reaction catalyzed by PFL does not change. Therefore, in C. celer the branched pyruvate node can serve as a safety valve relieving the cell from the burden of ferredoxin reoxidation in unfavorable conditions and thus avoiding a decrease in the metabolic flux.

\section{Effect of culture $\mathrm{pH}$ on growth and fermentative metabolism of $\mathrm{C}$. celer}

In previous studies performed under non-controlled conditions the optimal initial $\mathrm{pH}$ for $\mathrm{H}_{2}$ accumulation in C. celer was observed to be 8.2 at $67^{\circ} \mathrm{C}$ (approximately 9.0 at room temperature) $[8,9]$ in accordance with the optimal $\mathrm{pH}$ for growth [21]. However, in non-pH-controlled conditions the dynamic $\mathrm{pH}$ profile caused by the production of organic acids masked the real effect of $\mathrm{pH}$ on the metabolism of $C$. celer. In the current study, pH-controlled fermentations using both 5 and $10 \mathrm{~g} / \mathrm{l}$ of glucose showed that alkaline to neutral $\mathrm{pH}$ (8 and 7 at room temperature) clearly favor high growth rates in $C$. celer confirming the alkalitolerant nature of this organism. On the other hand, at moderately acidic $\mathrm{pH}$ (6 and 5.5 at room temperature) the $\mu_{\max }$ was reduced by 2 to 3 -fold (Table 1,2 ) regardless of the $P_{\mathrm{H} 2}$ in the system. However, with $10 \mathrm{~g} / \mathrm{l}$ of glucose in the medium, growth ceased before complete glucose depletion and the biomass yield was identical for all the conditions (Table 2). This could be caused by nutrient limitation or by inhibiting conditions such as increased osmolality and accumulation of by-products in the culture [13,22]. When $C$. celer grew at high rates in alkaline/neutral conditions, biomass formation was more energy-efficient despite the lower overall ATP recovery from glucose (Table 1, 3). In contrast, at acidic $\mathrm{pH}$ the growth rates were reduced and inefficient biomass formation was observed despite the more effective energy recovery. Given the alkalitolerant nature of $C$. celer, it is likely that at suboptimal extracellular $\mathrm{pH}$ this organism needs to maintain the intracellular $\mathrm{pH}$ within the physiological range. This goal can be achieved by $\mathrm{H}^{+}$-ATPase which exports protons at the expense of ATP hydrolysis. The activity of this enzyme is known to increase at low intracellular $\mathrm{pH}$, thus consuming a substantial portion of the intracellular ATP produced via substrate level phosphorylation [23,24]. Based on the intracellular ATP levels measured at different culture $\mathrm{pH}$ conditions (Table 3) and the flux of ATP hydrolysis (v21) (Figure 2B), it can be hypothesized that in $C$. celer at lower $\mathrm{pH}$ non-growth-associated ATP consumption increases most probably to achieve cytoplasmic $\mathrm{pH}$ homeostasis.

An analysis of the end-product distribution clearly indicated that $C$. celer exhibited different metabolic patterns depending on the culture $\mathrm{pH}$. Surprisingly, at moderately acidic $\mathrm{pH}$ conversion of glucose to $\mathrm{H}_{2}$ was more favorable ( $>2 \mathrm{~mol} \mathrm{H}_{2} / \mathrm{mol}$ glucose) than at alkaline 
to neutral pHs ( $<2 \mathrm{~mol} \mathrm{H}_{2} / \mathrm{mol}$ glucose $)$ as a consequence of the lower synthesis of other reduced byproducts, i.e. formate and ethanol (Tables 1, 2). On the other hand, volumetric $\mathrm{H}_{2}$ productivity was directly correlated with $\mu_{\max }$, both increasing as $\mathrm{pH}$ was shifted to alkaline $\mathrm{pH}$. Notably, a transition in the metabolic behavior of $C$. celer was observed between pH 7 and 6 (Tables 1, 2). In particular, both the formate yield and the formate flux during exponential phase were more than 2-fold higher at $\mathrm{pH} 7$ regardless of the $P_{\mathrm{H} 2}$ in the reactor (Table 2; Figures 2B, 3B). A widespread tendency among PFL-encoding organisms to accumulate formate during glucose fermentation as culture $\mathrm{pH}$ becomes more neutral/alkaline was observed, albeit with different magnitude, both in pure [25-32] and mixed cultures [33,34]. In absence of a formate hydrogen lyase (FHL) in C. celer and other strictly anaerobic bacteria the synthesis of formate by PFL competes with generation of $\mathrm{H}_{2}$ [19].

Although at this stage the exact mechanism of this metabolic shift triggered by culture $\mathrm{pH}$ in $C$. celer is unknown, several hypotheses can be proposed: i) a simultaneous anabolic and catabolic role of PFL, as reported in closely related clostridia [35], would justify the higher flux through PFL observed at elevated growth rates in this (Figure 4A) and previous studies [9] possibly to meet energy and anabolic demands at optimal $\mathrm{pH}$ for growth; ii) since pyruvate can trigger its own utilization by PFL participating as allosteric effector in the activation of this enzyme [36,37] and acetyl-CoA can inhibit PFOR [38-40], at elevated growth rates observed at neutral/alkaline $\mathrm{pH}$ higher pyruvate and acetyl-CoA fluxes favored the reaction catalyzed by PFL, whereas pyruvate was mainly directed to PFOR under reduced pyruvate and acetyl-CoA fluxes observed at lower growth rates in acidic conditions and in the transition from the exponential to the stationary phase (Figures 2B, 3B, 4B); iii) the activity of PFL is optimal at $\mathrm{pH}$ slightly above 7 , but reduced under acidic conditions [37,41]; iv) while the $\Delta \mathrm{G}^{\mathrm{o}}$ of the reaction catalyzed by PFL is not affected by $\mathrm{pH}$, the reoxidation of $\mathrm{Fd}_{\text {red }}$ via proton reduction necessary to drive the oxidative pyruvate dissimilation by PFOR, becomes less favorable as the $\mathrm{pH}$ increases [27]. Overall, given the direct correlation between flux distribution at the pyruvate node during exponential phase and $\mathrm{H}_{2}$ yield (Figure $4 \mathrm{~B}$ ), carbon and electron flow should be channeled through PFOR instead of PFL to maximize $\mathrm{H}_{2}$ synthesis.

Unlike formate, ethanol production does not seem to be dependent on $\mathrm{pH}$ culture. In fact, at $5 \mathrm{~g} / \mathrm{l}$ of glucose with $\mathrm{N}_{2}$ sparging the highest ethanol yield (0.48 $\mathrm{mol} / \mathrm{mol}$ glucose) was achieved at $\mathrm{pH} 7$ and the lowest $(0.20 \mathrm{~mol} / \mathrm{mol}$ glucose $)$ at $\mathrm{pH} 6$ (Table 1$)$. However, ethanol yields at $\mathrm{pH} 8$ and 5.5 were similar. Moreover, at high $P_{\mathrm{H} 2}$ no difference was observed between $\mathrm{pH} 7$ and 6 (Table 2). This suggests that regulation of carbon flux through the acetyl-CoA branch point could potentially serve as a means of controlling the disposal of reducing equivalents necessary to maintain an internal redox balance.

\section{Effect of $P_{\mathrm{H} 2}$ on growth and fermentative metabolism of C. celer}

The results obtained in this study show that under controlled conditions $P_{\mathrm{H} 2}$ does not affect the growth of $C$. celer. Both biomass formation and bioenergetics parameters $\left(\mathrm{Y}_{\mathrm{X} / \mathrm{ATP}}\right.$ and $\left.\mathrm{Y}_{\mathrm{ATP} / \mathrm{S}}\right)$ were the same regardless the $P_{\mathrm{H} 2}$ (Figure 1A; Table 2). Also growth rate and consequently volumetric $\mathrm{H}_{2}$ productivity were not dependent on $P_{\mathrm{H} 2}$ (Table 2). Under given conditions, the growth rate is dependent on the glycolytic flux which, in turn, is a function of the activity of GAPDH. The activity of GAPDH is negatively affected by an increase of the $\mathrm{NADH} / \mathrm{NAD}^{+}$ratio $[42,43]$. During batch cultivations the $\mathrm{NADH} / \mathrm{NAD}^{+}$in $C$. celer was low at exponential phase at both $\mathrm{pH}$ (Table 3), suggesting a complete $\mathrm{NADH}$ reoxidation regardless of the $P_{\mathrm{H} 2}$. As a consequence, the flux through GAPDH $(v 4)$ was not inhibited by high $P_{\mathrm{H} 2}$ (Figure 2B). Unlike other anaerobic bacteria which employ alternative pathways to $\mathrm{H}_{2}$ production for the reoxidation of $\mathrm{NADH}$ (e.g. ethanol and lactate production) only in response to high $\mathrm{NADH} / \mathrm{NAD}^{+}$ $[43,44]$, in C. celer the ethanol production started already in the exponential phase (Figure 1F) preventing the $\mathrm{NADH} / \mathrm{NAD}^{+}$to increase and inhibit GAPDH. As a result, in the conditions at which NADH-dependent $\mathrm{H}_{2}$ formation is supposed to be inhibited by high $P_{\mathrm{H} 2}$ (Case II and $I V$ ) ethanol yield is higher (Table 2). $\mathrm{NADH}$ was maintained at low levels also in the stationary phase (Table 3). At this stage reoxidation of $\mathrm{NADH}$ through ethanol synthesis followed a $\mathrm{pH}$-dependent pattern as at $\mathrm{pH} 7$ ethanol flux $(v 17)$ and accumulation were still significant, while at pH 6 almost ceased (Figures 1F, 3C).

The pyruvate node is another important metabolic point for the management of reducing equivalents. Indeed, at high $P_{\mathrm{H} 2}$ the overall formate yield and its flux $(v 14)$ in the exponential phase were higher suggesting that the non-oxidative reaction catalyzed by PFL serves as an alternative route for pyruvate dissimilation at high $\mathrm{H}_{2}$ concentration. In fact, while acetyl-CoA production by PFOR produces one pair of reducing equivalents $\left(F d_{\text {red }}\right)$, in the PFL reaction the reducing equivalents remain with the product formate. Thus, regulation of carbon flux at the pyruvate node could potentially serve as an effective means of controlling the disposal of reducing equivalents necessary to maintain an internal redox balance. Additionally, this electron rerouting was 
pH-dependent since in Case II ( $\mathrm{pH} 7$ without $\mathrm{N}_{2}$ sparging) formate was accumulated also in the stationary phase and $25.9 \%$ of the flux at the pyruvate node was directed through PFL, whereas in all the other conditions formate accumulation and flux almost ceased at this stage of growth. Increased formate yield in response to high $P_{\mathrm{H} 2}$ was reported also for Clostridium thermocellum $[45,46]$. Formate production has never been previously proposed as a pathway to control redox balance in the cell, probably due to the scarce occurrence of a similarly branched pyruvate node in other strict anaerobes.

The majority of the flux being directed to acetate production in all conditions (Figures 2B, 3C) seems to suggest that $C$. celer aims for maximization of ATP production to sustain high growth rate at alkaline/neutral $\mathrm{pH}$ or mechanisms for intracellular $\mathrm{pH}$ homeostasis at acidic $\mathrm{pH}$. According to the metabolic reconstruction (Figure 2A; Additional file 1: Table S1), four combinations of pathways for glucose catabolism are possible in C. celer (Eq. (1-4)):

$$
\begin{aligned}
\text { Glucose } & +4 \mathrm{H}_{2} \mathrm{O} \rightarrow 2 \text { Acetate }^{-}+2 \mathrm{HCO}_{3}{ }^{-} \\
& +4 \mathrm{H}^{+}+4 \mathrm{H}_{2}(4 \mathrm{ATP})
\end{aligned}
$$

$$
\begin{aligned}
\text { Glucose } & +3 \mathrm{H}_{2} \mathrm{O} \rightarrow 1 \text { Acetate }^{-}+1 \text { Ethanol }+2 \mathrm{HCO}_{3}{ }^{-} \\
& +3 \mathrm{H}^{+}+2 \mathrm{H}_{2}(3 \mathrm{ATP})
\end{aligned}
$$

$$
\begin{aligned}
\text { Glucose } & +2 \mathrm{H}_{2} \mathrm{O} \rightarrow 2 \text { Acetate }^{-}+2 \text { Formate }^{-} \\
& +4 \mathrm{H}^{+}+2 \mathrm{H}_{2}(4 \mathrm{ATP})
\end{aligned}
$$

$$
\begin{aligned}
\text { Glucose } & +1 \mathrm{H}_{2} \mathrm{O} \rightarrow 1 \text { Acetate }^{-}+1 \text { Ethanol } \\
& +2 \text { Formate }^{-}+3 \mathrm{H}^{+}(3 \mathrm{ATP})
\end{aligned}
$$

Eqs. (1-3) direct $100 \%$ of the carbon flux through PFOR (v15), whereas Eqs. (3-4) direct the flux entirely through PFL (v14). Conversion of glucose to acetate by Eq. (1) allows for maximal ATP generation (4 ATP) by completely relying on hydrogenase activity to regenerate reduced cofactors (NADH and $\mathrm{Fd}_{\text {red }}$ ). However, at high $\mathrm{H}_{2}$ concentration hydrogenases are inhibited and less-energy efficient pathways for disposal of reducing equivalents need to be activated to sustain the catabolic flux. Indeed, at $70^{\circ} \mathrm{C}$ and $1 \mathrm{M}$ of dissolved $\mathrm{H}_{2}$ this reaction is the least thermodynamically favorable $\left(\Delta \mathrm{G}^{\prime}{ }_{70}^{\circ} \mathrm{C}=-153.1 \mathrm{~kJ}\right)$, but becomes more favorable as $\mathrm{H}_{2}$ concentration decreases (Additional file 2: Figure S1). The metabolic setup of C. celer allows for a reaction yielding 3 ATP (Eq. (4)) whose $\Delta \mathrm{G}^{\prime}{ }_{70^{\circ} \mathrm{C}}$ is completely independent of the $\mathrm{H}_{2}$ concentration (Additional file 2: Figure S1). Conversely, reactions thermodynamically independent of the $\mathrm{H}_{2}$ concentration used by other fermentative bacteria for balancing high $\mathrm{NADH} / \mathrm{NAD}^{+}$(e.g. ethanol and lactate synthesis) yield only
2 ATP $[12,43,44]$. Thus Eq. (4) ensures C. celer a higher energy-recovery from glucose breakdown and unaltered glycolytic flux even under unfavorable conditions for $\mathrm{H}_{2}$ production. In addition, $C$. celer can potentially still obtain 4 ATP through Eq. (3) which is slightly more favorable at high $\mathrm{H}_{2}$ concentrations than Eq. (1) (Additional file 2: Figure S1).

As shown by the inverse correlation between ethanol and formate fluxes with the two components of $\mathrm{H}_{2}$ flux (Figure 5A, B, C), ethanol and formate production serves as an alternative to $\mathrm{H}_{2}$ production for maintaining the redox balance in the cell when hydrogenases are inhibited: $\mathrm{ADH}$ assists $\mathrm{NADH}$-dependent hydrogenase to keep low NADH levels, while PFL simultaneously supplies acetyl-CoA and stores reducing equivalents in formate thus regulating the pool of $\mathrm{Fd}_{\text {red }}$ available for $\mathrm{Fd}$-dependent hydrogenase. Given the stoichiometry of the fermentations and the distribution of the fluxes, C. celer utilizes a combination of the putative pathways to balance anabolic and catabolic requirements as well as intracellular redox state depending on the conditions. One exception can, however, be observed in Case III ( $\mathrm{pH} 6$ with $\mathrm{N}_{2}$ sparging) when $C$. celer entered the stationary phase. Under these conditions an equal contribution by the two components of the $\mathrm{H}_{2}$ flux and a normalized $\mathrm{H}_{2}$ flux close to the theoretical stoichiometric coefficient of 4 were observed (Figure 3D). Since no ethanol and formate production as well as biomass synthesis were detected, the fermentation proceeded according to Eq. (1). As previously observed [9], in C. celer the complete reoxidation of both $\mathrm{Fd}_{\text {red }}$ and $\mathrm{NADH}$ through $\mathrm{H}_{2}$ production occurred at low $\mathrm{pH}$ and $P_{\mathrm{H} 2}$ when glucose was used for non-growth associated cell maintenance.

\section{Conclusions}

Combining experimental results from batch fermentations, with genome analysis, reconstruction of central carbon metabolism and metabolic flux analysis (MFA), this study shed light on glucose catabolism of the thermophilic alkalitolerant bacterium $C$. celer. This organism possesses a flexible fermentative metabolism that allows efficient energy harvesting from substrate even under unfavorable conditions (i.e. low $\mathrm{pH}$ and high $P_{\mathrm{H} 2}$ ). Two innate factors pertaining to culture conditions have been identified to significantly affect the metabolic flux distribution: culture $\mathrm{pH}$ and $P_{\mathrm{H} 2}$.

Overall, at alkaline to neutral $\mathrm{pH}$ the rate of biomass synthesis of $C$. celer is maximized and the flux at the pyruvate node mainly directed to PFL suggesting a higher activity of this enzyme as well as a possible role in anabolic metabolism. On the other hand, at acidic $\mathrm{pH}$ the lower growth rate and the less efficient biomass formation are accompanied with a more efficient energy recovery from the substrate indicating a high cell 
maintenance requirement possibly to sustain intracellular $\mathrm{pH}$ homeostasis. Higher $\mathrm{H}_{2}$ yields were associated with fermentation at acidic $\mathrm{pH}$ as a consequence of lower synthesis of other reduced by-products such as formate and ethanol. In contrast, $P_{\mathrm{H} 2}$ does not affect growth of $C$. celer on glucose. At high $P_{\mathrm{H} 2}$ the cellular redox state was balanced by rerouting the flow of carbon and electrons to ethanol and formate production allowing unaltered glycolytic flux and growth rate, but resulting in a decreased $\mathrm{H}_{2}$ synthesis. Overall, with the optimization of $\mathrm{H}_{2}$ production in mind, C. celer offers the flexibility of shifting from a high yield-oriented process (at acidic $\mathrm{pH}$ with $\mathrm{N}_{2}$ sparging) to a high productivityoriented process (at alkaline $\mathrm{pH}$ without $\mathrm{N}_{2}$ sparging). In particular, the tolerance exhibited by $C$. celer towards $\mathrm{H}_{2}$ build-up in the reactor is attractive because $\mathrm{H}_{2}$ production should be achieved preferably without the need for sparging gas to reduce capital costs for the gasupgrading process [47]. The metabolic control and regulation of the pyruvate node as well as the genetic, metabolic and physiological traits that allow C. celer to withstand high $P_{\mathrm{H} 2}$ merit further studies.

\section{Materials and methods}

\section{Microorganism and medium}

Caloramator celer strain JW/YL-NZ35, former Thermobrachium celere (equivalent to DSMZ 8682 and ATCC 700318), was obtained from the Deutsche Sammlung von Mikroorganismen und Zellkulturen (Braunschweig, Germany). C. celer was cultivated in a modified ATCC 2072 medium.

(www.lgcstandards-atcc.org/ /media/4866DB6C29C449 38B4B62542D2152259.ashx) containing (per liter): $\mathrm{KH}_{2} \mathrm{PO}_{4}$ 0.75 g; $\mathrm{Na}_{2} \mathrm{HPO}_{4} \cdot 2 \mathrm{H}_{2} \mathrm{O} 1.53 \mathrm{~g}$; $\mathrm{KCl} 1 \mathrm{~g} ;\left(\mathrm{NH}_{4}\right)_{2} \mathrm{SO}_{4} 0.5 \mathrm{~g}$; $\mathrm{NH}_{4} \mathrm{Cl} 0.5 \mathrm{~g} ; \mathrm{MgCl}_{2} \cdot 6 \mathrm{H}_{2} \mathrm{O} 0.1 \mathrm{~g} ; \mathrm{CaCl}_{2} \cdot 6 \mathrm{H}_{2} \mathrm{O} 0.11 \mathrm{~g}$; $\mathrm{FeSO}_{4} \cdot 7 \mathrm{H}_{2} \mathrm{O} 0.2 \mathrm{~g}$; cystein- $\mathrm{HCl} 0.2 \mathrm{~g}$; resazurin $0.001 \mathrm{~g}$; trace element solution $10 \mathrm{ml}$; vitamin solution $10 \mathrm{ml}$; yeast extract $2 \mathrm{~g}$; tryptone $2 \mathrm{~g}$; glucose 5 or $10 \mathrm{~g}$. Stock solutions under nitrogen atmosphere containing glucose, cystein- $\mathrm{HCl}, \mathrm{MgCl}_{2} \cdot 6 \mathrm{H}_{2} \mathrm{O}, \mathrm{CaCl}_{2} \cdot 6 \mathrm{H}_{2} \mathrm{O}, \mathrm{FeSO}_{4} \cdot 7 \mathrm{H}_{2} 0$ and vitamins were sterilized separately and added anaerobically to autoclaved medium at the required concentrations. Routine subcultures and inoculum development were conducted in $250 \mathrm{ml}$ serum bottles containing $50 \mathrm{ml}$ of medium at $67^{\circ} \mathrm{C}$.

\section{Growth conditions}

Cultures were grown in a jacketed, 3-liter bioreactor equipped with an ADI 1025 Bio-Console and an ADI 1010 Bio-Controller (Applikon, Schiedam, The Netherlands) at a working volume of $1 \mathrm{l}$. The initial $\mathrm{pH}$ was maintained at $67^{\circ} \mathrm{C}$ by automatic titration with $4 \mathrm{M} \mathrm{NaOH}$. The temperature was thermostatically kept at $67 \pm 1^{\circ} \mathrm{C}$ and the stirring rate was set to $250 \mathrm{rpm}$. A condenser with $5^{\circ} \mathrm{C}$ cooling water was fitted to the bioreactor's headplate. Prior to inoculation, the medium was sparged with $\mathrm{N}_{2}$ and supplemented with an anoxic solution of cysteine- $\mathrm{HCl}$ at a final concentration of $0.2 \mathrm{~g} / \mathrm{l}$ to make the medium completely anaerobic along with the other stock solutions. Glucose was used as a primary substrate in all experiments at an initial concentration of 5 or $10 \mathrm{~g} / \mathrm{l}$. The medium was inoculated with $50 \mathrm{ml}(5 \% \mathrm{v} / \mathrm{v})$ of a culture in the exponential phase.

The effect of culture $\mathrm{pH}$ on the fermentative metabolism of C. celer was studied at four different $\mathrm{pH}$ values $(8,7,6$ and 5.5) measured at room temperature. In this experiment the bioreactor was constantly sparged with $\mathrm{N}_{2}$ at $100 \mathrm{ml} / \mathrm{min}$. Glucose was added as substrate in concentration of $5 \mathrm{~g} / \mathrm{l}$. The effect of $P_{\mathrm{H} 2}$ at two $\mathrm{pH}$ levels (7 and 6) was investigated by applying two experimental conditions: continuous $\mathrm{N}_{2}$ sparging at $100 \mathrm{ml} / \mathrm{min}$ for continuous removal of produced $\mathrm{H}_{2}$ (Case $\mathrm{I}$ at $\mathrm{pH} 7$ and Case III at pH 6) and in absence of $\mathrm{N}_{2}$ sparging with the bioreactor's gas outlet open to allow accumulation of $\mathrm{H}_{2}$ in the headspace at atmospheric pressure (Case II at $\mathrm{pH} 7$ and Case $I V$ at $\mathrm{pH}$ 6). In the latter experimental condition the overall gas production was obtained by measuring the volume of displaced $\mathrm{NaHCO}_{3}$-saturated solution in a graduated cylinder. In this experiment glucose was added as substrate in concentration of $10 \mathrm{~g} / \mathrm{l}$. Gas samples from the headspace for $\mathrm{H}_{2}$ and $\mathrm{CO}_{2}$ determination and culture samples for monitoring growth, substrate consumption and metabolite formation were regularly withdrawn during growth. Samples for the measurement of intracellular ATP, NADH and $\mathrm{NAD}^{+}$concentrations were collected as described earlier [48] during the exponential and stationary phase of the cultivations supplemented with $10 \mathrm{~g} / \mathrm{l}$ glucose. All the experimental conditions were performed in biological duplicates and included negative controls omitting glucose.

\section{Analytical methods}

Headspace samples were analyzed for $\mathrm{H}_{2}$ and $\mathrm{CO}_{2}$ concentration by gas chromatography, using a dual channel CP-4900 Micro-GC (Varian, Middelburg, The Netherlands) as described earlier [49]. The results were analyzed with a Galaxie Chromatography Workstation (v.1.9.3.2). Cell concentrations were determined by measuring the absorbance at $620 \mathrm{~nm}$ using a spectrophotometer (Ultrospec 2100 pro, Amesham Biosciences, UK). Cell dry weight (CDW) was determined as described earlier [44]. Glucose, acetate, formate, ethanol and butyrate were analyzed by HPLC (Waters, Milford, USA) on an Aminex HPX-87H ion exchange column (Bio-Rad, Hercules, USA) at $45^{\circ} \mathrm{C}$, with $5 \mathrm{mM} \mathrm{H}_{2} \mathrm{SO}_{4}\left(0.6 \mathrm{ml} \mathrm{min}{ }^{-1}\right)$ as the mobile phase. The column was equipped with a refractive index detector (RID-6A, Shimadzu, Japan). 


\section{$\mathrm{NAD}(\mathrm{H})$ assay}

Cell culture samples $(1 \mathrm{ml})$ were collected in the exponential and stationary phase of growth for $\mathrm{NADH}$ and $\mathrm{NAD}^{+}$ determination. Samples were immediately quenched by transferring them to a microcentrifuge tube containing $1 \mathrm{ml}$ of ice and centrifuged for $1 \mathrm{~min}$ at $12,100 \mathrm{~g}$. The pellets were immediately frozen and stored at $-80^{\circ} \mathrm{C}$ until further analysis. Intracellular concentrations of NADH and $\mathrm{NAD}^{+}$were determined by a cyclic assay as described earlier [48]. Intracellular levels of $\mathrm{NADH}$ and $\mathrm{NAD}^{+}$ were expressed per $1 \mathrm{~g}$ of CDW.

\section{Measurement of ATP}

Cell culture samples $(1 \mathrm{ml})$ were collected in the exponential and stationary phase of growth for ATP determinations. Samples were collected in screw-cap microcentrifuge tubes containing $1 \mathrm{ml}$ of ice-cold chloroform and immediately frozen into liquid nitrogen. Samples were stored at $-80^{\circ} \mathrm{C}$ until further analysis. Intracellular concentrations of ATP were measured with an ATP Bioluminescence assay kit HSII (Roche Molecular Biochemicals, Germany) as described earlier [48]. Intracellular levels of ATP were expressed per $1 \mathrm{~g}$ of $\mathrm{CDW}$.

\section{Calculations}

$\mathrm{H}_{2}$ accumulation $\left(\mathrm{mmol} \mathrm{H}_{2} / \mathrm{l}\right.$ ) was calculated in two different ways depending on the experimental design. When $\mathrm{N}_{2}$ sparging was applied the calculations were based on the flow rate of the influent $\mathrm{N}_{2}$ gas and the percentages of $\mathrm{H}_{2}$ and $\mathrm{CO}_{2}$ in the effluent gas, whereas when $\mathrm{N}_{2}$ sparging was not applied the flow rate of the effluent gas was measured by the liquid displacement method using a $\mathrm{NaCO}_{3}$-saturated solution to avoid any further $\mathrm{CO}_{2}$ solubilization. Molar $\mathrm{H}_{2}$ and $\mathrm{CO}_{2}$ were calculated using the ideal gas law based on their concentration in the effluent gas. Volumetric $\mathrm{H}_{2}$ productivity $\left(Q_{\mathrm{H} 2} ; \mathrm{mmol} \mathrm{H}_{2} / \mathrm{l} / \mathrm{h}\right)$ was determined from the slope of the straight line obtained by plotting the cumulative $\mathrm{H}_{2}\left(\mathrm{mmol} \mathrm{H}_{2} / \mathrm{l}\right)$ against the time (h) during exponential growth.

Carbon balances were calculated from the total amount of carbon-containing products formed (in C-mol) and the amount of sugar consumed (in C-mol). Electron balances were calculated after multiplying the amount of each metabolite and sugar by the corresponding degree of reduction (in mol electrons per $\mathrm{C}$-mol). The chemical formula of biomass was assumed to be $\mathrm{CH}_{1.8} \mathrm{O}_{0.5} \mathrm{~N}_{0.2}$. Metabolite yields as well as carbon and electron balances were calculated by subtracting the background metabolite production in control cultivations (i.e. cultivation without the substrate) and the precultures' carryover metabolites from the results.

The yield of biomass per ATP $\left(\mathrm{Y}_{\mathrm{X} / \mathrm{ATP}} ; \mathrm{g}_{\mathrm{CDW}} / \mathrm{mol}\right.$ ATP) and the ATP yield ( $\mathrm{Y}_{\mathrm{ATP} / \mathrm{s}}$; mol ATP/mol glucose) were calculated based on the Eq. (5) and Eq. (6), respectively.

$$
\begin{aligned}
& \mathrm{Y}_{\mathrm{X} / \mathrm{ATP}}=\frac{[\text { biomass }]}{2 *[\text { acetate }]+1 *[\text { ethanol }]} \\
& \mathrm{Y}_{\mathrm{ATP} / \mathrm{S}}=\frac{2 *[\text { acetate }]+1 *[\text { ethanol }]}{[\text { glucose consumed }]}
\end{aligned}
$$

The calculation assumes that C. celer uses a PEPdependent phosphotransferase system (PTS) for glucose uptake. Specific rates of substrate consumption uptake and metabolite formation $(r)$ were calculated according to

$$
r=\frac{\mathrm{dC}}{\mathrm{dt}} * \mathrm{X}
$$

where $r$ is the specific production rate $\left(\mathrm{mmol} / \mathrm{g}_{\mathrm{CDW}} / \mathrm{h}\right)$, $\mathrm{C}$ is the substrate or metabolite concentration $(\mathrm{mM})$ and $\mathrm{X}$ is the biomass $\left(\mathrm{g}_{\mathrm{CDW}}\right)$.

\section{In silico model construction and metabolic flux analysis}

The genome of C. celer strain JW/YL-NZ35 has been recently sequenced and a high quality draft sequence has been annotated as described earlier [18]. The available genomic data was used to reconstruct the central carbon metabolism of C. celer and to build a stoichiometric model including glycolytic pathway, pentose phosphate pathway, end product synthesis pathways, transport mechanisms and biomass synthesis. In order to define each reaction and metabolite in the network, genes encoding for putative enzymes involved in the aforementioned pathways were identified by manual curation of the data from the annotated genome by a combination of sequence alignments [50], gene context analysis, database and literature searches. In addition, physiological evidences were used either when association between genes and reactions could not be established or when a reaction was removed from the network despite a corresponding gene being identified in the genome. The final model consisted of 24 reactions and 20 intracellular metabolites (Additional file 1: Table S1).

Metabolic flux analysis (MFA) was employed to calculate the unknown intracellular fluxes at different stages of $C$. celer's growth (exponential, transition and stationary phase) under the tested conditions. A metabolic matrix was constructed based on the model according to the law of mass conservation and on the pseudo-steady state hypothesis for the intracellular metabolites. Given the overdetermined nature of the system, the mass balance equations for all the metabolites were expressed in matrix form as:

$$
\mathrm{V}_{\mathrm{c}}=-\mathrm{G}_{\mathrm{c}}^{*} \times \mathrm{G}_{\mathrm{m}} \times \mathrm{V}_{\mathrm{m}}
$$

where $V_{c}$ is the calculated flux vector, $G_{c}^{*}$ is pseudo-inverse matrix of the calculated reactions, $G_{m}$ is the matrix of the 
measured reactions and $\mathrm{V}_{\mathrm{m}}$ the measured flux vector. The matrix of MFA model was solved with MATLAB R2013a (The MathWorks, Inc., Natick, USA).

\section{Additional files}

Additional file 1: Table S1. Reconstructed genomic model of the central carbon metabolism in Caloramator celer.

Additional file 2: Figure S1. Effect of the $\mathrm{H}_{2}$ concentration on the Gibbs energy change $\left(\Delta \mathrm{G}^{\prime}\right)$ at $70^{\circ} \mathrm{C}$ of four predicted reactions involved in glucose fermentation in $\mathrm{C}$. celer.

\section{Competing interests}

The authors declare that they have no competing interests.

\section{Authors' contributions}

AC, SSP and EWJVN designed the study. AC and SSP planned and preformed the batch experiments. AC planned and preformed NAD $(H)$ and ATP quantifications and metabolite analysis. AC and SSP performed metabolic flux analysis. AC wrote the manuscript. SSP, VS, MK and EWJVN participated in manuscript drafting. VS, MK and EWJVN supervised and coordinated the study. All authors have read and approved the manuscript.

\section{Acknowledgements}

Alessandra Radici is kindly acknowledged for language editing of the manuscript. AC acknowledges support from the Academy of Finland (grants no.126974, 139830, 272602), the Finnish Doctoral Programme in Environmental Science and Technology (EnSTe) and Tampere University of Technology Graduate School. SSP acknowledges support from the Swedish Research Council (VR).

\section{Author details}

${ }^{1}$ Department of Chemistry and Bioengineering, Tampere University of Technology, Korkeakoulunkatu 8, Fl-33720 Tampere, Finland. ${ }^{2}$ Department of Applied Microbiology, Lund University, P.O. Box 124, SE-221 00 Lund, Sweden.

Received: 10 February 2014 Accepted: 18 March 2014

Published: 28 March 2014

\section{References}

1. Kapdan IK, Kargi F: Bio-hydrogen production from waste materials. Enzyme Microb Technol 2006, 38:569-582.

2. Lattin WC, Utgikar VP: Transition to hydrogen economy in the United States: A 2006 status report. Int J Hydrogen Energy 2007, 32:3230-3237.

3. Hallenbeck PC, Ghosh D: Advances in fermentative biohydrogen production: the way forward? Trends Biotechnol 2009, 27:287-297.

4. Rittmann S, Herwig C: A comprehensive and quantitative review of dark fermentative biohydrogen production. Microb Cell Fact 2012, 11:115.

5. Verhaart MRA, Bielen AAM, van der Oost J, Stams AJM, Kengen SWM: Hydrogen production by hyperthermophilic and extremely thermophilic bacteria and archaea: mechanisms for reductant disposal. Environ Technol 2010, 31:993-1003

6. Baena S, Patel B: Genus V: Caloramator Collins, Lawson, Willems, Cordoba, Fernández-Garayzábal, Garcia, Cai, Hippe and Farrow 1994, $812^{\mathrm{VP}}$ emend. Chrisostomos, Patel, Dwivedi and Denman 1996, 497. In Bergey's manual of systematic bacteriology. Volume 3: The Firmicutes. 2nd edition. Edited by De Vos P, Garrity G, Jones D, Krieg N, Ludwig W, Rainey F, Schleifer K, Whitman W. New York, NY: Springer-Verlag; 2009:834-838.

7. Koskinen PEP, Lay C, Puhakka JA, Lin P, Wu S, Örlygsson J, Lin C: High-efficiency hydrogen production by an anaerobic, thermophilic enrichment culture from an icelandic hot spring. Biotechnol Bioeng 2008, 101:665-678.

8. Ciranna A, Santala V, Karp M: Biohydrogen production in alkalithermophilic conditions: Thermobrachium celere as a case study. Bioresour Technol 2011, 102:8714-8722.

9. Ciranna A, Santala V, Karp M: Enhancing biohydrogen production of the alkalithermophile Thermobrachium celere. Int J Hydrogen Energy 2012, 37:5550-5558.
10. Kengen SM, Stams AJM, de Vos WM: Sugar metabolism of hyperthermophiles FEMS Microbiol Rev 1996, 18:119-137.

11. Schröder $C$, Selig $M$, Schönheit $P$ : Glucose fermentation to acetate, $\mathrm{CO}_{2}$ and $\mathrm{H}_{2}$ in the anaerobic hyperthermophilic eubacterium Thermotoga maritima: involvement of the Embden-Meyerhof pathway. Arch Microbiol 1994, 161:460-470.

12. Soboh B, Linder D, Hedderich R: A multisubunit membrane-bound [NiFe] hydrogenase and an NADH-dependent Fe-only hydrogenase in the fermenting bacterium Thermoanaerobacter tengcongensis. Microbiology 2004, 150:2451-2463.

13. van Niel EWJ, Claassen PAM, Stams AJM: Substrate and product inhibition of hydrogen production by the extreme thermophile, Caldicellulosiruptor saccharolyticus. Biotechnol Bioeng 2003, 81:255-262.

14. Ljunggren M, Willquist K, Zacchi G, Van Niel EWJ: A kinetic model for quantitative evaluation of the effect of hydrogen and osmolarity on hydrogen production by Caldicellulosiruptor saccharolyticus. Biotechnol Biofuels 2011, 4:31.

15. Zhang $F$, Zhang $Y$, Chen M, Zeng RJ: Hydrogen supersaturation in thermophilic mixed culture fermentation. Int J Hydrogen Energy 2012, 37:17809-17816.

16. Wang J, Wan W: Factors influencing fermentative hydrogen production: A review. Int J Hydrogen Energy 2009, 34:799-811.

17. Hawkes FR, Dinsdale R, Hawkes DL, Hussy I: Sustainable fermentative hydrogen production: Challenges for process optimisation. Int J Hydrogen Energy 2002, 27:1339-1347

18. Ciranna A, Larjo A, Kivistö A, Santala V, Roos C, Karp M: Draft Genome Sequence of the Hydrogen- and Ethanol-Producing Anaerobic Alkalithermophilic Bacterium Caloramator celer. Genome Announc 2013, 1:e00471-13.

19. Carere CR, Rydzak T, Verbeke TJ, Cicek N, Levin DB, Sparling R: Linking genome content to biofuel production yields: A meta-analysis of major catabolic pathways among select $\mathrm{H}_{2}$ and ethanol-producing bacteria. BMC Microbiology 2012, 12:295.

20. Sapra R, Bagramyan $K$, Adams MWW: A simple energy-conserving system: Proton reduction coupled to proton translocation. Proc Natl Acad Sci USA 2003, 100:7545-7550.

21. Engle M, Li Y, Rainey F, DeBlois S, Mai V, Reichert A, Mayer F, Messner P, Wiegel J: Thermobrachium celere gen. nov., sp. nov., a rapidly growing thermophilic, alkalitolerant, and proteolytic obligate anaerobe. Int I Syst Bacteriol 1996, 46:1025-1033.

22. Ciranna A, Ferrari R, Santala V, Karp M: Inhibitory effects of substrate and soluble end products on biohydrogen production of the alkalithermophile Caloramator celer: kinetic, metabolic and transcription analyses. Int J Hydrogen Energy 2014, 39:6391-6401.

23. Kobayashi H: Regulation of cytoplasmic pH in streptococci. In Sugar transport and metabolism in Gram-positive bacteria. Edited by Reizer J, Peterkofsky A. London, United Kingdom: Ellis Harwood; 1987.

24. O'Sullivan E, Condon S: Relationship between acid tolerance, cytoplasmic $\mathrm{pH}$, and ATP and $\mathrm{H}^{+}$-ATPase levels in chemostat cultures of Lactococcus lactis. Appl Environ Microbiol 1999, 65:2287-2293.

25. Kessler D, Knappe J: Anaerobic dissimilation of pyruvate. In Escherichia coli and Salmonella: cellular and molecular biology. 2nd edition. Edited by Neidhardt FC, Curtiss R III, Ingraham JL, Lin ECC, Low KB, Magasanik B, Reznikoff WS, Riley M, Schaechter M, Umbarger HE. Washington, DC: ASM Press; 1996:199-204.

26. Sridhar J, Eiteman MA: Metabolic flux analysis of Clostridium thermosuccinogenes: Effects of $\mathrm{pH}$ and culture redox potential. Appl Biochem Biotechnol 2001, 94:51-69.

27. Liu IC, Whang LM, Ren WJ, Lin PY: The effect of $\mathrm{pH}$ on the production of biohydrogen by clostridia: Thermodynamic and metabolic considerations. Int J Hydrogen Energy 2011, 36:439-449.

28. Combet-Blanc Y, Kalamba KK, Kergoat PY: Effect of pH on Bacillus thermoamylovorans growth and glucose fermentation. Appl Environ Microbiol 1995, 61:656-659.

29. Su Y, Rhee MS, Ingram LO, Shanmugam KT: Physiological and fermentation properties of Bacillus coagulans and a mutant lacking fermentative lactate dehydrogenase activity. J Ind Microbiol Biotechnol 2011, 38:441-450.

30. Koussémon M, Combet-Blanc $Y$, Ollivier B: Glucose fermentation by Propionibacterium microaerophilum: Effect of $\mathrm{pH}$ on metabolism and bioenergetic. Curr Microbiol 2003, 46:141-145.

31. Asanuma N, Iwamoto M, Hino T: Structure and transcriptional regulation of the gene encoding pyruvate formate-lyase of a ruminal bacterium Streptococcus bovis. Microbiology 1999, 145:151-157. 
32. Even S, Lindley ND, Cocaign-Bousquet M: Transcriptional, translational and metabolic regulation of glycolysis in Lactococcus lactis subsp. cremoris MG 1363 grown in continuous acidic cultures. Microbiology 2003, 149:1935-1944.

33. Temudo MF, Kleerebezem R, Van Loosdrecht M: Influence of the $\mathrm{pH}$ on (Open) mixed culture fermentation of glucose: A chemostat study. Biotechnol Bioeng 2007, 98:69-79.

34. Lee H, Rittmann BE: Evaluation of metabolism using stoichiometry in fermentative biohydrogen. Biotechnol Bioeng 2009, 102:749-758.

35. Thauer RK, Kirchniawy FH, Jungermann KA: Properties and function of the pyruvate-formate-lyase reaction in clostridiae. Eur J Biochem 1972, 27:282-290.

36. Takahashi-Abbe S, Abe K, Takahashi N: Biochemical and functional properties of a pyruvate formate-lyase (PFL)-activating system in Streptococcus mutans. Oral Microbiol Immunol 2003, 18:293-297.

37. Knappe J, Blaschkowski HP, Gröbner P, Schmitt T: Pyruvate Formate-Lyase of Escherichia coli: the Acetyl-Enzyme Intermediate. Eur J Biochem 1974, 50:253-263.

38. Kerscher L, Oesterhelt D: The catalytic mechanism of 2-oxoacid: Ferredoxin oxidoreductases from Halobacterium halobium. One electron transfer at two distinct steps of the catalytic cycle. Eur J Biochem 1981, 116:595-600.

39. Williams K, Lowe PN, Leadlay PF: Purification and characterization of pyruvate: ferredoxin oxidoreductase from the anaerobic protozoon Trichomonas vaginalis. Biochem J 1987, 246:529-536.

40. Pineda E, Encalada R, Rodríguez-Zavala JS, Olivos-García A, Moreno-Sánchez R, Saavedra E: Pyruvate:ferredoxin oxidoreductase and bifunctional aldehyde-alcohol dehydrogenase are essential for energy metabolism under oxidative stress in Entamoeba histolytica. FEBS Journal 2010, 277:3382-3395.

41. Asanuma N, Hino T: Effects of $\mathrm{pH}$ and energy supply on activity and amount of pyruvate formate-lyase in Streptococcus bovis. Appl Environ Microbiol 2000, 66:3773-3777.

42. Payot S, Guedon E, Cailliez C, Gelhaye E, Petitdemange H: Metabolism of cellobiose by Clostridium cellulolyticum growing in continuous culture: Evidence for decreased NADH reoxidation as a factor limiting growth. Microbiology 1998, 144:375-384.

43. Payot S, Guedon E, Gelhaye E, Petitdemange H: Induction of lactate production associated with a decrease in NADH cell content enables growth resumption of Clostridium cellulolyticumin batch cultures on cellobiose. Res Microbiol 1999, 150:465-473.

44. Willquist $\mathrm{K}$, van Niel EWJ: Lactate formation in Caldicellulosiruptor saccharolyticusis regulated by the energy carriers pyrophosphate and ATP. Metab Eng 2010, 12:282-290.

45. Rydzak T, Levin DB, Cicek N, Sparling R: End-product induced metabolic shifts in Clostridium thermocellum ATCC 27405. Appl Microbiol Biotechnol 2011, 92:199-209.

46. Carere C, Rydzak T, Cicek N, Levin D, Sparling R: Role of transcription and enzyme activities in redistribution of carbon and electron flux in response to $\mathrm{N}_{2}$ and $\mathrm{H}_{2}$ sparging of open-batch cultures of Clostridium thermocellum ATCC 27405. Appl Microbiol Biotechnol 2014, 98:2829-2840.

47. Ljunggren M, Zacchi G: Techno-economic analysis of a two-step biological process producing hydrogen and methane. Bioresour Technol 2010 101:7780-7788.

48. Willquist K, Pawar S, Van Niel E: Reassessment of hydrogen tolerance in Caldicellulosiruptor saccharolyticus. Microb Cell Fact 2011, 10:111.

49. Zeidan AA, van Niel EWJ: A quantitative analysis of hydrogen production efficiency of the extreme thermophile Caldicellulosiruptor owensensis OLT. Int J Hydrogen Energy 2010, 35:1128-1137.

50. Altschul SF, Madden TL, Schäffer AA, Zhang J, Zhang Z, Miller W, Lipman DJ: Gapped BLAST and PSI-BLAST: A new generation of protein database search programs. Nucleic Acids Res 1997, 25:3389-3402.

\section{doi:10.1186/1475-2859-13-48}

Cite this article as: Ciranna et al: Assessment of metabolic flux distribution in the thermophilic hydrogen producer Caloramator celer as affected by external $\mathrm{pH}$ and hydrogen partial pressure. Microbial Cell Factories 2014 13:48.

\section{Submit your next manuscript to BioMed Central and take full advantage of:}

- Convenient online submission

- Thorough peer review

- No space constraints or color figure charges

- Immediate publication on acceptance

- Inclusion in PubMed, CAS, Scopus and Google Scholar

- Research which is freely available for redistribution 